Article

\title{
Artificial Neural Network Led Optimization of Oxyhydrogen Hybridized Diesel Operated Engine
}

\author{
Muhammad Usman 1,*(D), Haris Hussain ${ }^{1}$, Fahid Riaz ${ }^{2}$ (D), Muneeb Irshad ${ }^{3}$, Rehmat Bashir ${ }^{1}$, \\ Muhammad Haris Shah ${ }^{1}$ (D), Adeel Ahmad Zafar ${ }^{1}$, Usman Bashir ${ }^{1}$, M. A. Kalam ${ }^{4, *(D), ~ M . ~ A . ~ M u j t a b a ~}{ }^{5, *(\mathbb{D})}$ \\ and Manzoore Elahi M. Soudagar ${ }^{6}$ (D)
}

1 Department of Mechanical Engineering, University of Engineering and Technology, Lahore 54890, Pakistan; haris.hussain@uet.edu.pk (H.H.); rehmatbshir@uet.edu.pk (R.B.); haris1049shah@outlook.com (M.H.S.); adeelzafar966@gmail.com (A.A.Z.); usman.bashir1002@gmail.com (U.B.)

2 Department of Mechanical Engineering, National University of Singapore, Singapore 117575, Singapore; fahid.riaz@u.nus.edu

3 Department of Physics, University of Engineering and Technology Lahore, Lahore 54890, Pakistan; muneeb_irshad@uet.edu.pk

4 Center for Energy Science, Department of Mechanical Engineering, University of Malaya, Kuala Lumpur 50603, Malaysia

5 Department of Mechanical Engineering, New Campus, University of Engineering and Technology, Lahore 54890, Pakistan

6 Department of Mechanical Engineering, School of Technology, Glocal University, Delhi-Yamunotri Marg, SH-57, Mirzapur Pole, Saharanpur 247121, Uttar Pradesh, India; me.soudagar@gmail.com

check for updates

Citation: Usman, M.; Hussain, H.; Riaz, F.; Irshad, M.; Bashir, R.; Haris Shah, M.; Ahmad Zafar, A.; Bashir, U.; Kalam, M.A.; Mujtaba, M.A.; et al. Artificial Neural Network Led Optimization of Oxyhydrogen Hybridized Diesel Operated Engine. Sustainability 2021, 13, 9373. https:// doi.org/10.3390/su13169373

Academic Editor: Mehdi Seyedmahmoudian

Received: 9 July 2021

Accepted: 17 August 2021

Published: 20 August 2021

Publisher's Note: MDPI stays neutral with regard to jurisdictional claims in published maps and institutional affiliations.

Copyright: (c) 2021 by the authors. Licensee MDPI, Basel, Switzerland. This article is an open access article distributed under the terms and conditions of the Creative Commons Attribution (CC BY) license (https:/ / creativecommons.org/licenses/by/ $4.0 /)$.
* Correspondence: muhammadusman@uet.edu.pk (M.U.); kalam@um.edu.my (M.A.K.); m.mujtaba@uet.edu.pk (M.A.M.)

Abstract: The prevailing massive exploitation of conventional fuels has staked the energy accessibility to future generations. The gloomy peril of inflated demand and depleting fuel reservoirs in the energy sector has supposedly instigated the urgent need for reliable alternative fuels. These very issues have been addressed by introducing oxyhydrogen gas (HHO) in compression ignition (CI) engines in various flow rates with diesel for assessing brake-specific fuel consumption (BSFC) and brake thermal efficiency (BTE). The enrichment of neat diesel fuel with $10 \mathrm{dm}^{3} / \mathrm{min}$ of HHO resulted in the most substantial decrease in BSFC and improved BTE at all test speeds in the range of 1000-2200 rpm. Moreover, an Artificial Intelligence (AI) approach was employed for designing an ANN performance-predicting model with an engine operating on $\mathrm{HHO}$. The correlation coefficients (R) of BSFC and BTE given by the ANN predicting model were 0.99764 and 0.99902 , respectively. The mean root errors (MRE) of both parameters (BSFC and BTE) were within the range of 1-3\% while the root mean square errors (RMSE) were $0.0122 \mathrm{~kg} / \mathrm{kWh}$ and $0.2768 \%$ for BSFC and BTE, respectively. In addition, ANN was coupled with the response surface methodology (RSM) technique for comprehending the individual impact of design parameters and their statistical interactions governing the output parameters. The $\mathrm{R}^{2}$ values of RSM responses (BSFC and BTE) were near to 1 and MRE values were within the designated range. The comparative evaluation of ANN and RSM predicting models revealed that MRE and RMSE of RSM models are also well within the desired range but to be outrightly accurate and precise, the choice of ANN should be potentially endorsed. Thus, the combined use of ANN and RSM could be used effectively for reliable predictions and effective study of statistical interactions.

Keywords: diesel; oxyhydrogen; artificial neural network; response surface methodology; prediction; desirability

\section{Introduction}

Ever-growing industrialization and unprecedented use of non-renewable fuels have brought us to a very feeble junction where we have to be a bit vigilant or we may run out 
of fossil fuels [1]. Hydrocarbon reserves found in nature are going to become extinct in the future if we continue using them without any restrictions because these reserves are being consumed at a rate faster than their formation [2,3]. The world energy demand is excessively soaring and is likely to be $28 \%$ higher in 2040 if consumption continues at the current pace. The intensifying pressure of depleting energy resources and fear of damage to the environment has consequently made scientists to look for alternative or green fuels. The use of oxygenated, alcoholic, and hydrogen fuels in CI engines has been the locus of interest of engineers for the past few years [4-10].

Compression ignition (CI) engines have long been the power generation source for heavy machinery in energy and aquatic transport owing to their high efficiency, torque, and feasibility of operation on a lean mixture of air and fuel [11]. Diesel is a commonly used fuel in CI engines. However, due to the incessant usage of fossil fuels to generate diesel, the focus of the researchers, engineers, and scientists made a paradigm shift towards the study of more efficient, promising, and greener fuels [12-16].

Hydrogen itself cannot be used in CI engines due to its high auto-ignition temperatures, which requires a very high compression ratio, but it can be mixed with fuel with low autoignition temperatures. Hydrogen gas is a good blending agent and could be effectively used in engines because of its low ignition temperature and high flammability [17]. The use of hydrogen as a mixing fuel is a concept with novelty and therefore much work has been reported. The earliest studies were conducted by T. Litzinger et al. on the operations of the IC Engines with multi-blended fuels. They validated the role of $\mathrm{H}_{2}$ inside the IC engines and found it as a potential replacement of fossil fuels [18]. Moreover, with scientific and technological development, many researchers have discovered that $\mathrm{H}_{2}$ can be used as a blend with other gases to reduce its combustibility and increase its ignition energy. H.K Abdel Aal carried out one such study to generate a safe method of $\mathrm{H}_{2}$ enrichment by using methane as a blending agent with $\mathrm{H}_{2}$. He used Le Chatelier's principle for predicting flammability and determining a safe ratio [19].

Similarly, among many fuels available for mixing, the use of diesel has also been an area of interest of researchers [20,21]. Kadir Aydin et al. conducted experimentation on a Mitsubishi 4 stroke CI engine using $\mathrm{HHO}$ gas $\mathrm{dm}^{3} / \mathrm{min}$ as a blended fuel with diesel. They observed a $19.1 \%$ increase in brake power (BP) and a $14 \%$ decrease in brake-specific fuel consumption (BSFC) with the addition of HHO as compared with simple diesel. Their study identified $1750 \mathrm{rpm}$ as a critical speed, below which the HHO addition was not favorable for engine performance [22]. Similarly, Alfredas et al. used an Audi 1.9 TDI (IZ type) $\mathrm{CI}$ engine to investigate the effect of $\mathrm{HHO}$ addition at three liters per minute (LPM) with diesel on the performance of the engine. Within the rpm range of 1900-3700, HHO proved to be favorable for engine performance [23]. Ali Yimilaz et al. also studied the outcome of $\mathrm{HHO}$ addition on engine performance and reported that engine torque was amplified by $19.1 \%$, and an average gain of $14 \%$ was achieved using HHO [24]. The effect of $\mathrm{HHO}$ gas on the performance of a Mitsubishi Canter brand, four-stroke, water-cooled diesel engine was conducted by Raif et al. They varied the flow rate of HHO from 3 LPM to 7 LPM and observed that with HHO enrichment, the torque and brake power increased, whereas fuel consumption decreased [25]. HHO has also the potential to be used as a blending agent with other fuels. In this regard, Usman et al. used HHO with LPG and CNG and reported improved performance and reduced emissions with the addition of HHO for both cases [26].

Owing to the cost and time of simply random experiments, researchers nowadays are utilizing computer systems to attain similar efficiency by performing the least number of experimental runs. Artificial neural network (ANN) and response surface methodology (RSM) techniques are currently used to solve problems in science and engineering, especially where classical modeling methods have pathetically failed. The predictive capability of the ANN model is based on the training of experimental data values and followed by validation. If new data values are not desired, the ANN model may re-learn to enhance the performance $[27,28]$. Raif Kenanoglu et al. used an artificial neural network for perfor- 
mance and emission analysis of a hydroxy gas-enriched CI engine for odd flow rates of 3.5 and $7 \mathrm{~L} / \mathrm{min}$. They used the Levenberg-Marquardt (LM) training function and found a $95.82 \%$ accuracy for torque [29]. Similarly, Yildrium et al. studied the effect of HHO enrichment on three different biodiesels using ANN. They used artificial intelligence for fixing optimum hydrogen enrichment and found that developed models had a coefficient of determination close to 1 [30].

Similarly, the RSM has the statistical regression technique for prediction [31,32]. Over the last few years, the combined application of ANN and RSM methods has been hailed with significant success in the power industry. Ghobadian et al. utilized diesel and biodiesel fuel blends for ANN-based prediction of performance and emission. The developed ANN model was viable with correlation coefficients (R-values) of 0.999 and 0.9487 for BSFC and torque, respectively [33]. The ANN coupled RSM-based optimization of SI engine was carried by Samet Uslu et al., which rendered the use of the ANN-supported RSM model as an effective tool for performance prediction [34].

Considering the literature cited, the use of ANN for predicting the performance of engines fueled with diesel HHO blends has already been studied [30]. However, the optimization of the engine with the same blend has not been reported so far. In the current study, ANN was used to predict the performance (BSFC and BTE) of a CI engine operating on diesel with HHO in flow rates of 2-10 LPM. Moreover, the ANN-assisted RSM optimization was applied to identify the optimized working conditions. The obtained optimum conditions were validated using experimentation. Thus, the combined use of artificial intelligence and RSM proved valuable in estimating and optimizing the performance of a $\mathrm{CI}$ engine.

\section{Materials and Methods}

\subsection{HHO Generator}

The HHO (hydroxy gas) was produced using an Ironside HHO Generator, shown in Figure 1. The features of the used HHO generator are itemized in Table 1. The power to the electrical unit was supplied using an AC source. Water was ionized using potassium hydroxide as a catalyst that generated hydrogen (positive charge) and hydroxide (negative charge) ions. On supplying the potential across ionized water, the generated HHO traversed first from a bubbler and later from a flow meter. Prior to injection in the engine's intake manifold, the flow rate of the gas was monitored using the flow meter. The potentiometer was connected with the electrical box for regulating the flow through the cell.

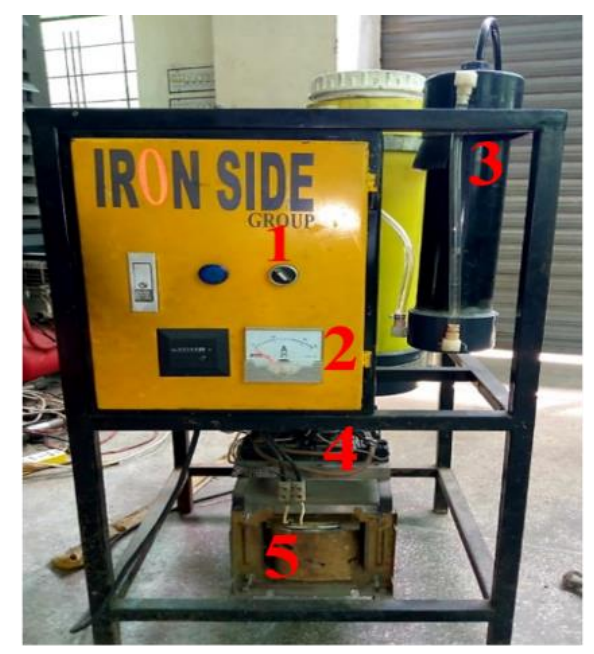

$$
\begin{array}{ll}
\text { 1. Control switch } & \text { 2. Ammeter } \\
\begin{array}{ll}
\text { 3. Bubbler } & \text { 4. Bridge rectifier }
\end{array}
\end{array}
$$

Figure 1. HHO generator. 
Table 1. HHO generator specifications.

\begin{tabular}{cc}
\hline Feature & Description \\
\hline Material of Plate & Stainless steel (316-1) \\
Dimensions of Plate & $16.5 \mathrm{~cm}$ by $16.5 \mathrm{~cm} \mathrm{by} 0.1 \mathrm{~cm}$ \\
Electrode configuration & Center anodes, end cathodes \\
Plate spacing & $2 \mathrm{~mm}$ \\
HHO flow rate & up to $10 \mathrm{LPM}$ \\
Maximum Voltage & $35 \mathrm{~V}$ \\
Maximum Current & $40 \mathrm{~A}$ \\
Relation between current and LPM & Direct relation up to 10 LPM \\
\hline
\end{tabular}

\subsection{Experimental Methodology and Test Fuels}

A direct injection, four-stroke, three-cylinder diesel engine was used for performance tests whose specifications are shown in Table 2. The speed, load, and fuel flow measuring system were equipped with the engine, as comprehensively demonstrated in the experimental setup (see Figure 2). The engine was attached with a 3-phase AC generator having $85 \%$ efficiency. Five breakers with equal loading capacity were utilized from the control unit, as shown in the schematic of the engine testbed (Figure 3). The loads were applied to the test engine utilizing the generator.

Table 2. Engine specifications.

\begin{tabular}{cc}
\hline Features & Description \\
\hline Engine type & Perkin/AD 3.152 \\
Bore & $91.4 \mathrm{~mm}$ \\
Stroke & $127.0 \mathrm{~mm}$ \\
Number of holes of nozzles & 4 \\
Brake mean effective pressure & $7.1570 \mathrm{bars}$ \\
Injection timing & $17^{0}$ BTDC \\
Displacement & $2.5 \mathrm{Liters}$ \\
Compression ratio & 18.5 \\
Maximum speed & $2200 \mathrm{rpm}$ \\
Maximum power & $36.8 \mathrm{~kW}$ at $1500 \mathrm{rpm}$ \\
Maximum torque & $243 \mathrm{~N} . \mathrm{m}$ at $1400 \mathrm{rpm}$ \\
\hline
\end{tabular}

The fuels used for conducting the experimental runs were pure diesel and HHO-mixed diesel with 2, 4, 6, 8, and 10 LPM enrichment. The physicochemical properties of liquid and gaseous fuels are shown in Table 3.

Table 3. Properties of fuels.

\begin{tabular}{ccc}
\hline Properties & Diesel & Hydrogen \\
\hline Research octane number & 30 & $>130$ \\
Density at $20^{\circ} \mathrm{C}$ & $833.1 \mathrm{~kg} / \mathrm{m}^{3}$ & $0.0827 \mathrm{~kg} / \mathrm{m}^{3}$ \\
Net heating value & $42.5 \mathrm{MJ} / \mathrm{kg}$ & $119.93 \mathrm{MJ} / \mathrm{kg}$ \\
Flame velocity & $30 \mathrm{~cm} / \mathrm{s}$ & $265-325 \mathrm{~cm} / \mathrm{s}$ \\
Autoignition temperature & $530 \mathrm{~K}$ & $858 \mathrm{~K}$ \\
Chemical composition & $\mathrm{C}_{12} \mathrm{H}_{23}$ & $\mathrm{H}_{2}$ \\
\hline
\end{tabular}




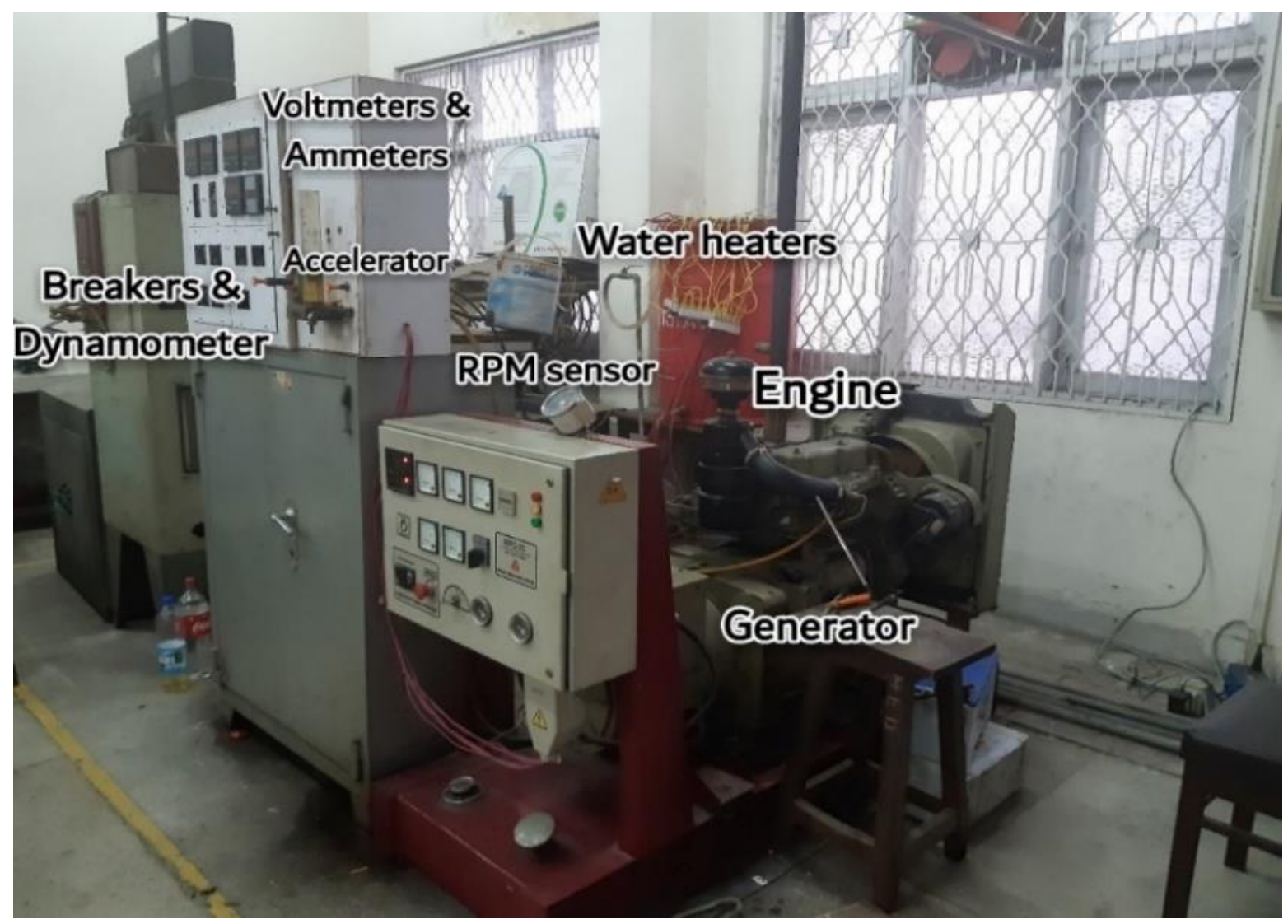

Figure 2. Experimental setup.

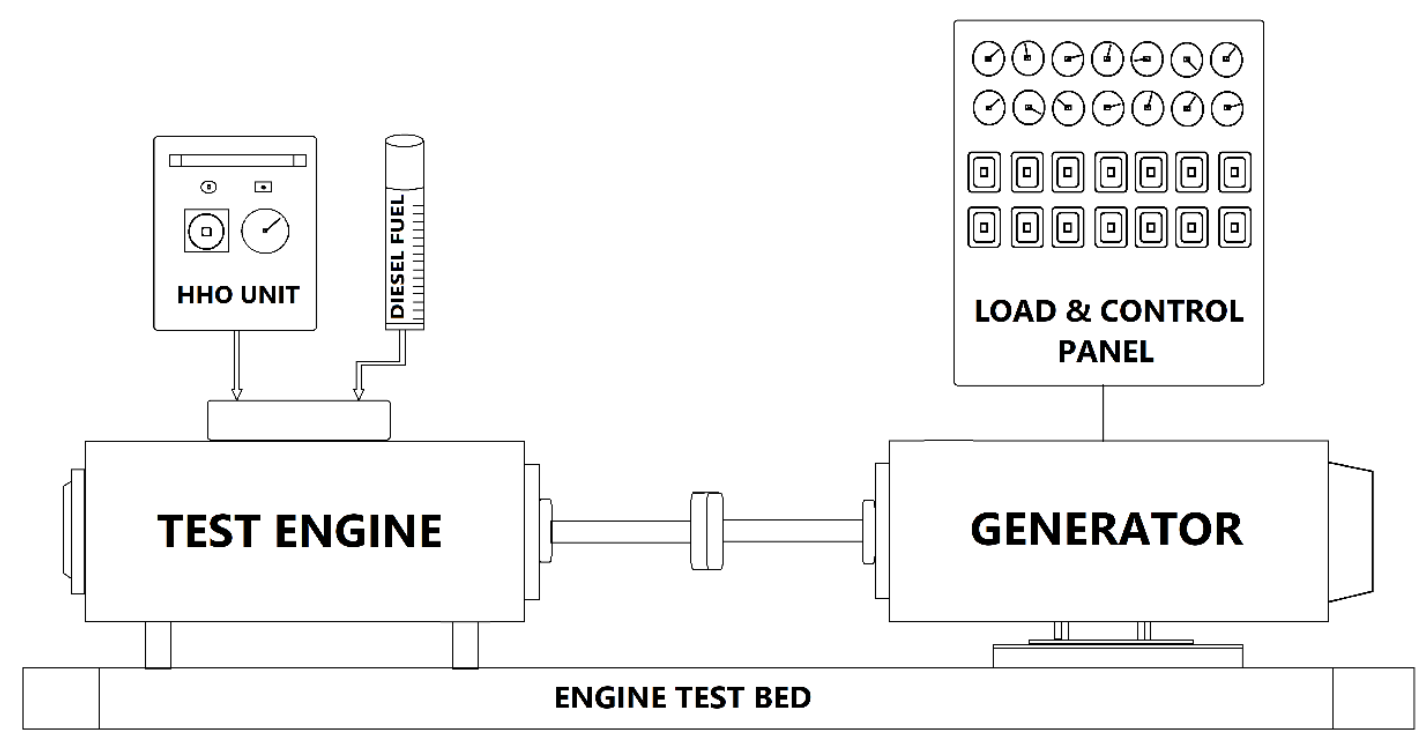

Figure 3. Schematic of engine test bed.

First, the diesel engine was allowed to warm up for $10 \mathrm{~min}$ ahead of recording the experimental observations. The tests were started at an engine speed of $1000 \mathrm{rpm}$ and ceased at $2200 \mathrm{rpm}$, with equal increments of $200 \mathrm{rpm}$ at each stage. The performance parameters, BSFC and BTE, were calculated at each constant strategic engine speed with 
varying loads $(9 \%, 18 \%, 27 \%, 36 \%, 45 \%)$ and $\mathrm{HHO}$ concentration of $2,4,6,8$, and $10 \mathrm{LPM}$ by using the following mathematical modelling equations:

$$
\begin{gathered}
\text { BTE }=\frac{\text { Break Power } \times 3600}{\text { Fuel Consumption } \times \text { Calorific Value }} \\
\text { BSFC }=\frac{\text { Fuel Consumption }}{\text { Break Power }}
\end{gathered}
$$

Considering all the possible combinations of continuously varying factors, 210 experimental observations were documented. The experimental work was restricted to lower half partial loading conditions considering the safety aspect associated with $\mathrm{HHO}$ utilization in engine. Moreover, using hydrogen accompanies better combustion and higher flame speed and temperature inside the engine, which may lead to thermal degradation if operated at higher loading conditions. Later, the ANN technique was implemented for designing the predictable model of engine performance. Finally, the performance was optimized using response surface methodology (RSM) and the desirability aspect was investigated.

\section{Experimental Results and Discussion}

Non-renewable fuels are normally associated with enhanced performance and reduced exhaust emissions [35]. Hydroxy gas is believed to facilitate cleaner and smoother combustion compared with conventional fuels. The experimental deliverables significantly demonstrated the decrease in BSFC and increase in BTE by virtue of $\mathrm{HHO}$ addition to diesel. The detailed effect of $\mathrm{HHO}$ on performance parameters is presented in the following sections.

\subsection{Brake Specific Fuel Consumption}

The patterns of BSFC variation with varying flow rate and engine load are shown in Figure 4a-g. The BSFC of all operating conditions of HHO enriched fuel was lower than for neat diesel. The addition of gaseous fuel to diesel evidenced promising fuel economy. At the speed of $2200 \mathrm{rpm}$ and a load of $9 \%$, the parameter (BSFC) differed by $12 \%$ for neat diesel and the one having $10 \mathrm{LPM}$ of $\mathrm{HHO}$, with the latter being more fuel-efficient. Similarly, the speed of $1600 \mathrm{rpm}$ rendered un-blended diesel less efficient on the account of an average of $8.44 \%$ higher fuel consumption when juxtaposed with 10 LPM HHO-enriched diesel. Moreover, the higher engine speeds seem to have a greater decrement in BSFC compared with low speeds. Equated at loads of $9 \%$ and $18 \%$ for speeds 1800 and $2200 \mathrm{rpm}$, the BSFC values diverged by 0.33 and $0.64 \mathrm{~kg} / \mathrm{kWh}$ for low and high speed, respectively. The higher flammability at higher speeds is the reason for augmented variations (decline) in BSFC for increased revolutions of the power-producing shaft. The improved fuel economy of the engine functioned with $\mathrm{HHO}$ could be apprehended by the high calorific value of hydrogen and efficient combustion due to the availability of oxygen atoms in the HHO structure [19,36-38]. 


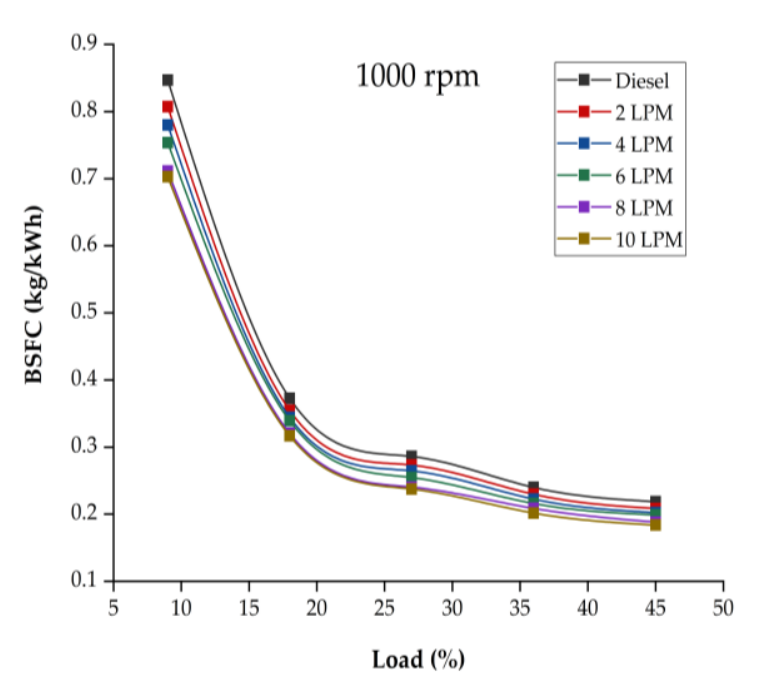

(a)

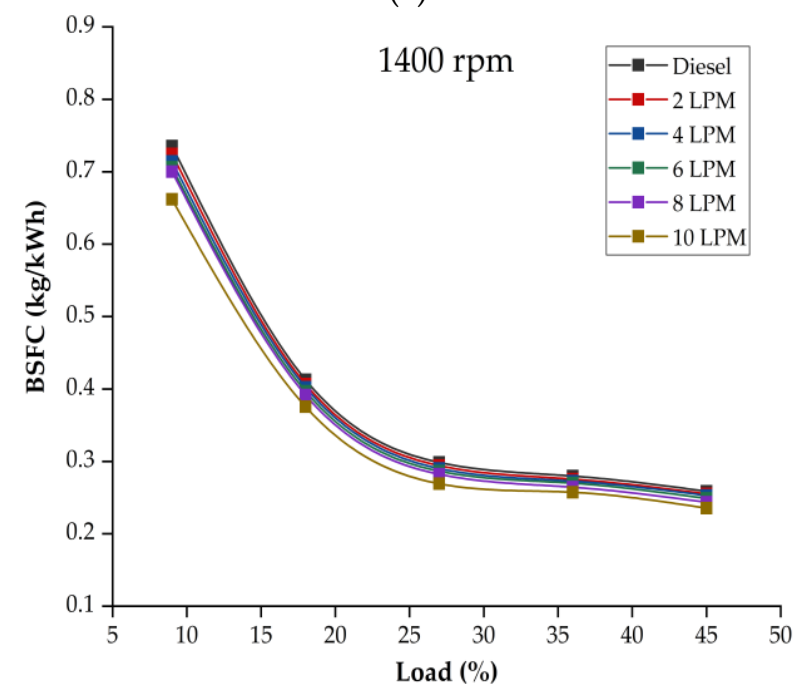

(c)

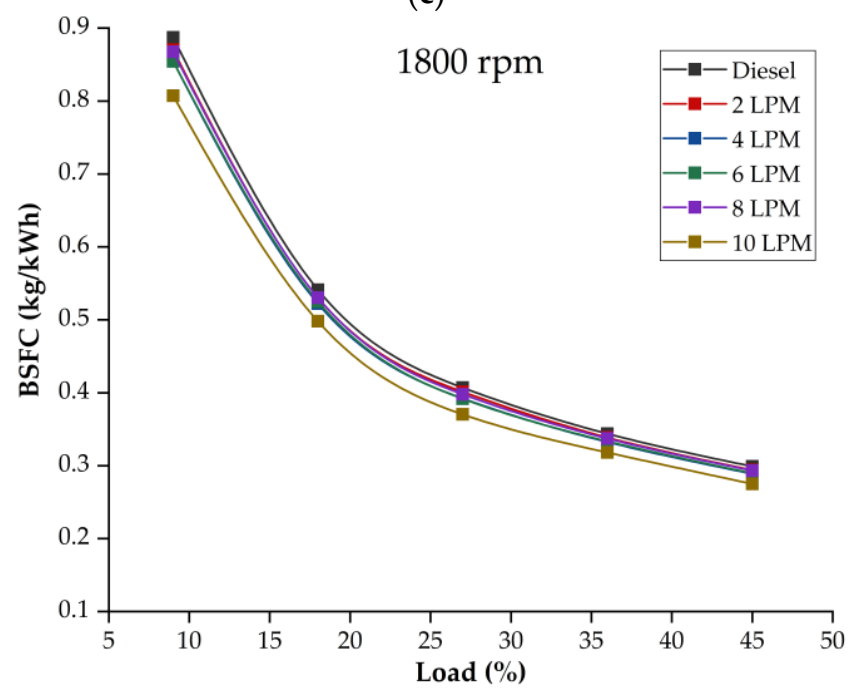

(e)

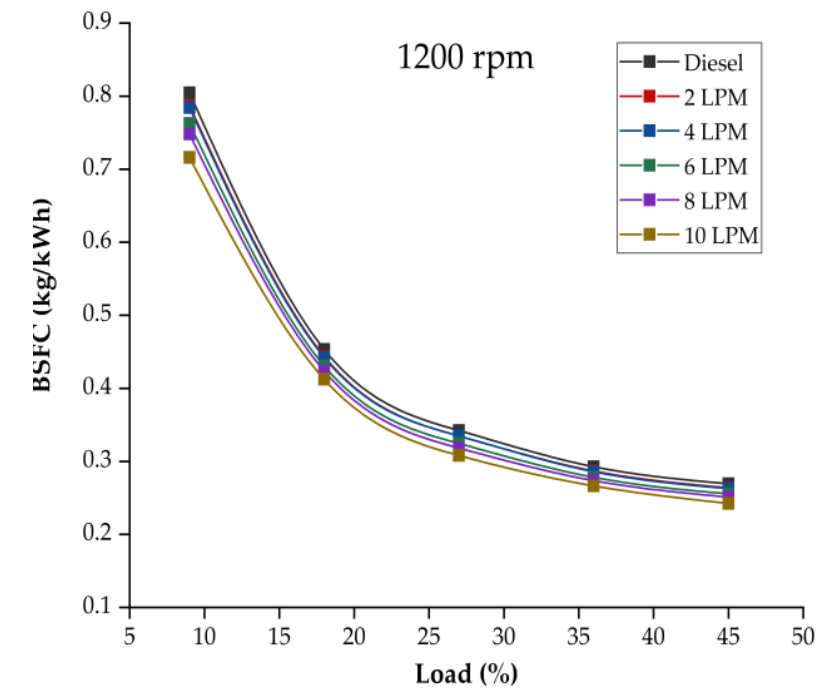

(b)

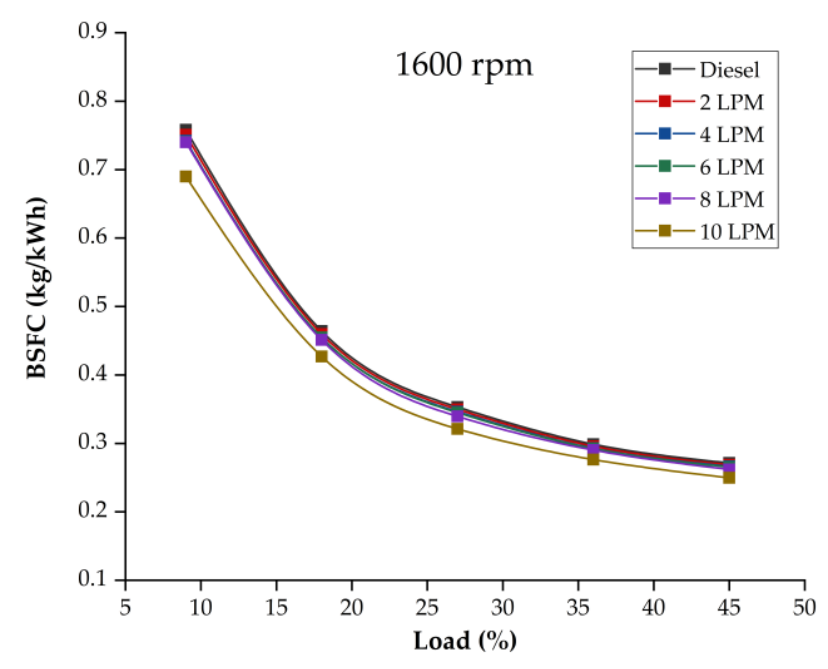

(d)

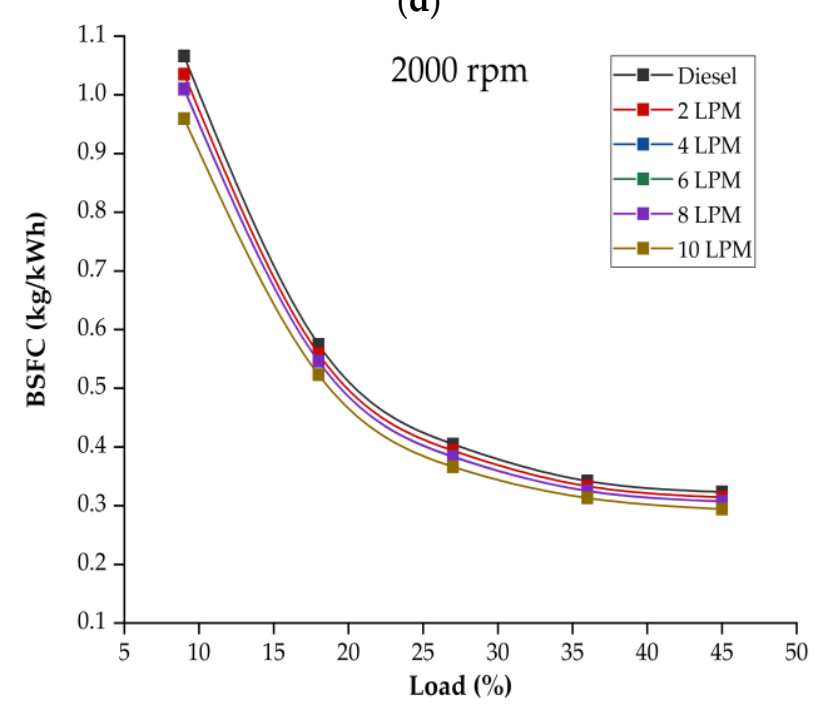

(f)

Figure 4. Cont. 


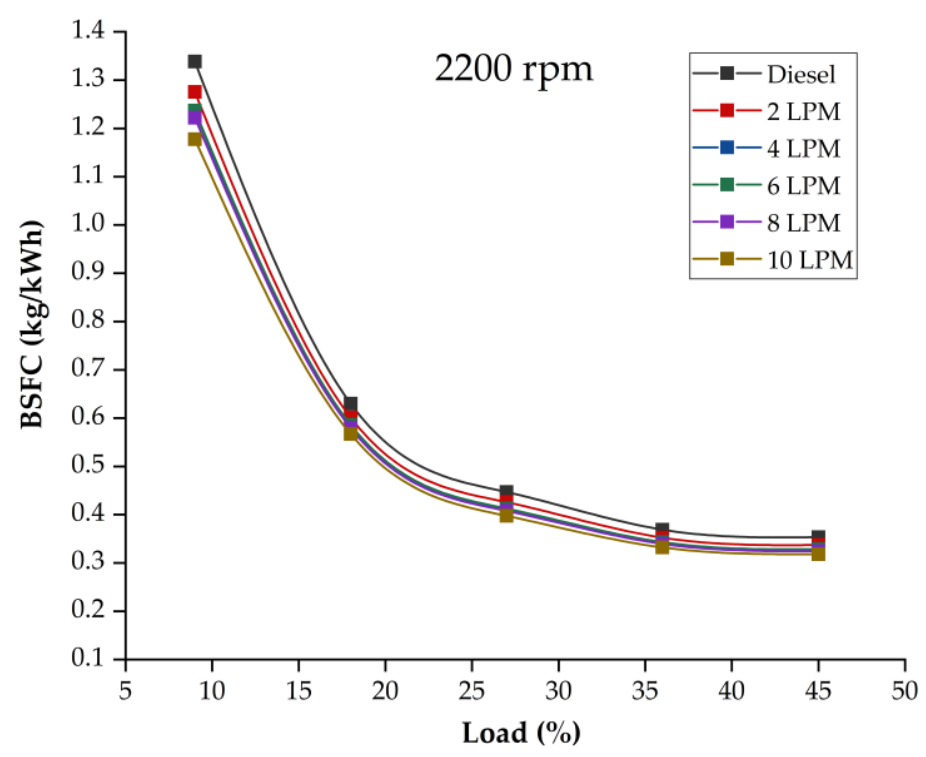

(g)

Figure 4. (a-g) Comparison of BSFC for diesel—HHO blends in speed range (1000-2200).

\subsection{Brake Thermal Efficiency}

Figure $5 \mathrm{a}-\mathrm{g}$ shows the brake thermal efficiencies of all operating conditions at different HHO flow rates and loads. Identical to BSFC, the engine exhibited boosted thermal efficiencies for all HHO-enriched fuels compared with pure diesel. The test speed of $1400 \mathrm{rpm}$ and flow rates of 2, 4, 6, 8, and $10 \mathrm{HHO}$ at the constant load of $18 \%$ returned BTE values of $11.11 \%, 19.80 \%, 27.37 \%, 29.16 \%$, and $31.55 \%$, respectively. Thus, with the successive addition of $\mathrm{HHO}$ to the pure diesel, the engine exhibited a more efficient behavior. Figure $5 \mathrm{c}$ is seen to be following a different pattern compared with other test speeds. The manufacturer provided the maximum torque of $243 \mathrm{Nm}$ at $1400 \mathrm{rpm}$ (see Table 2). Therefore, at $36 \%$ loading condition for $1400 \mathrm{rpm}$, the fuel consumption was observed as higher, which resulted in a lower rate of increase in BTE, as made evident by the part of curve after the $25 \%$ load. Of all the experimental runs, the maximum recorded efficiency was $42.39 \%$ at the following conditions: $1000 \mathrm{rpm}, 10 \mathrm{LPM} \mathrm{HHO}$, and $45 \%$ load. Compared at a speed of $2000 \mathrm{rpm}$, diesel with 10 LPM HHO presented an average of $9.07 \%$ better performance than neat fuel. The chemical structure of diesel reveals the presence of 23 hydrogen atoms. The addition of hydroxy gas augments the number of hydrogen atoms and hydrogen to carbon ratio increases, which could be held accountable for significantly improved efficiency [39]. Moreover, enhanced combustion, the high calorific value of fuel mixture, diffusivity, and fast flame propagation speed of hydrogen are the phenomena governing the better performance of the engine $[29,30,40,41]$. 


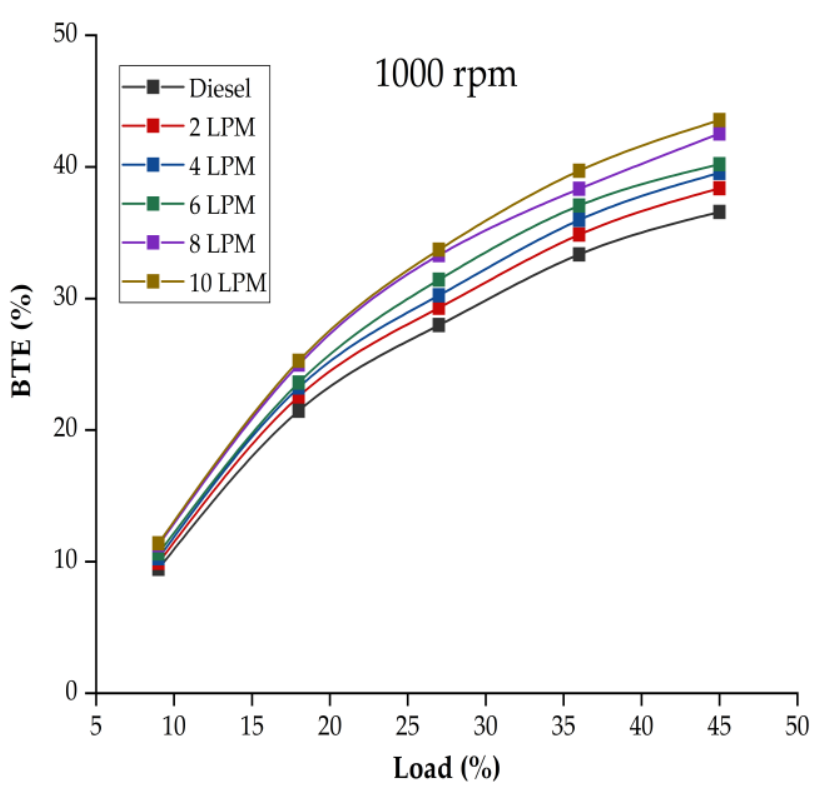

(a)

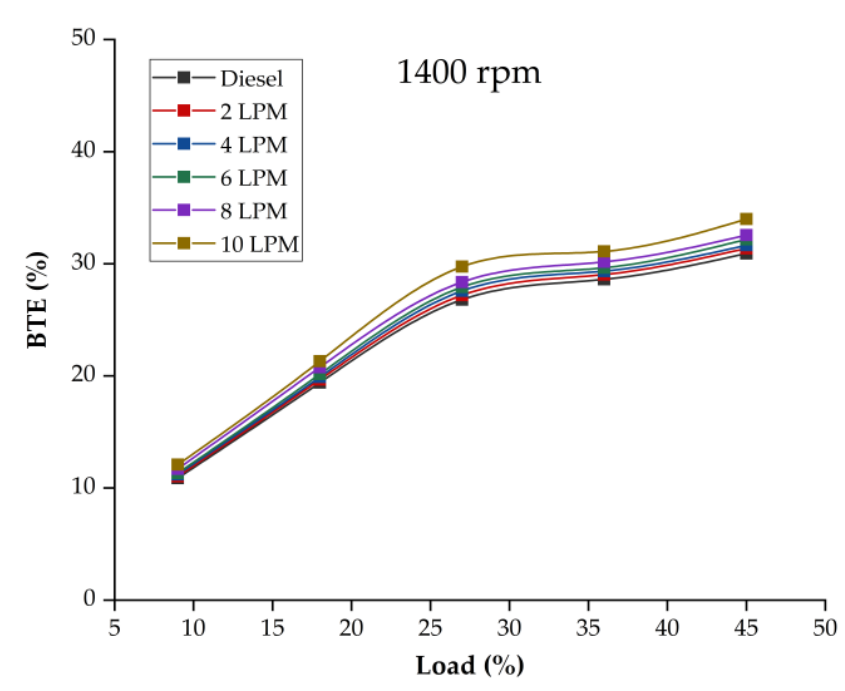

(c)

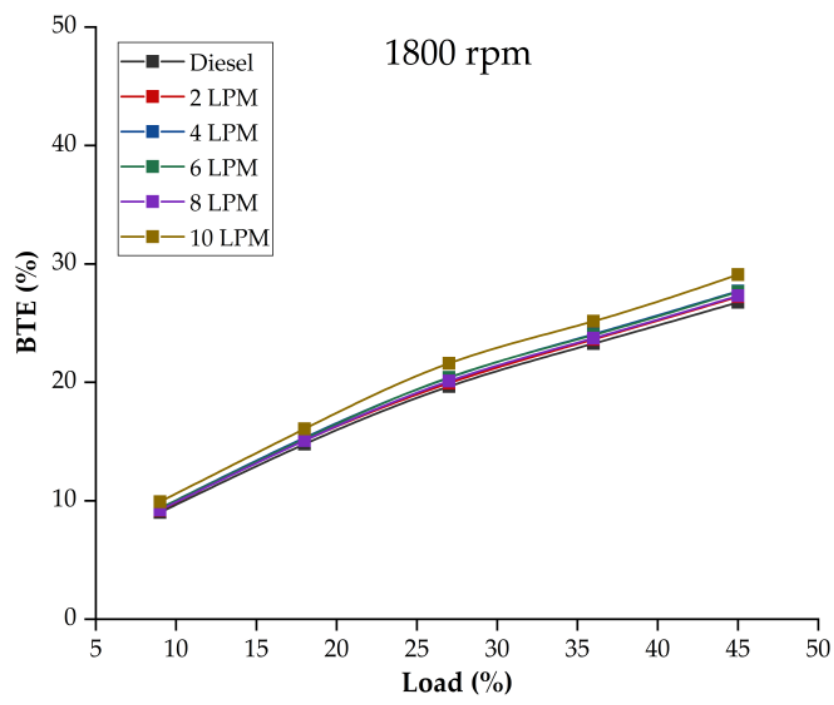

(e)

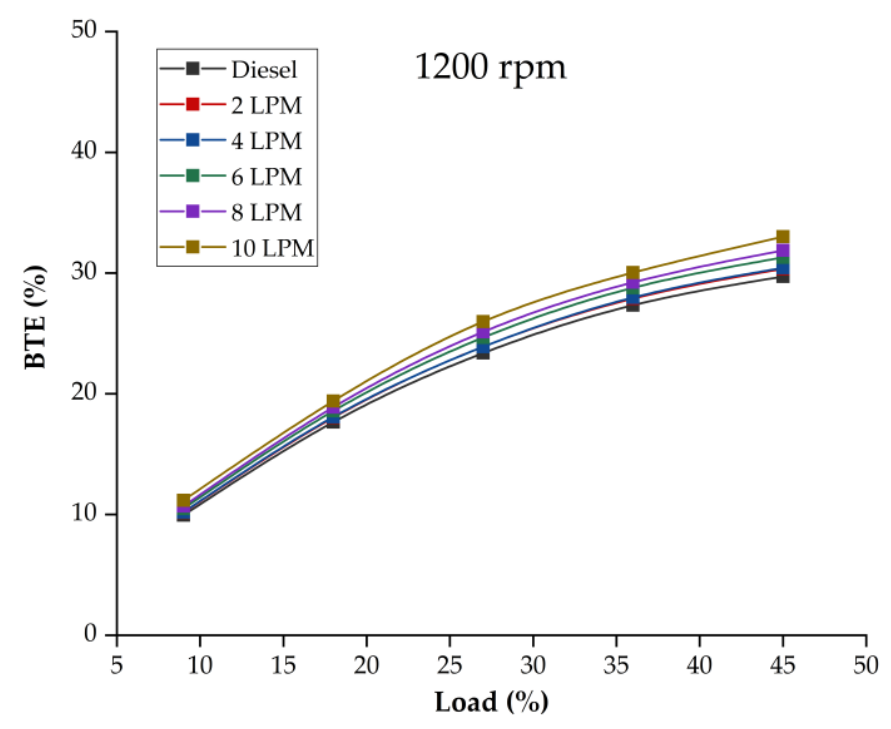

(b)

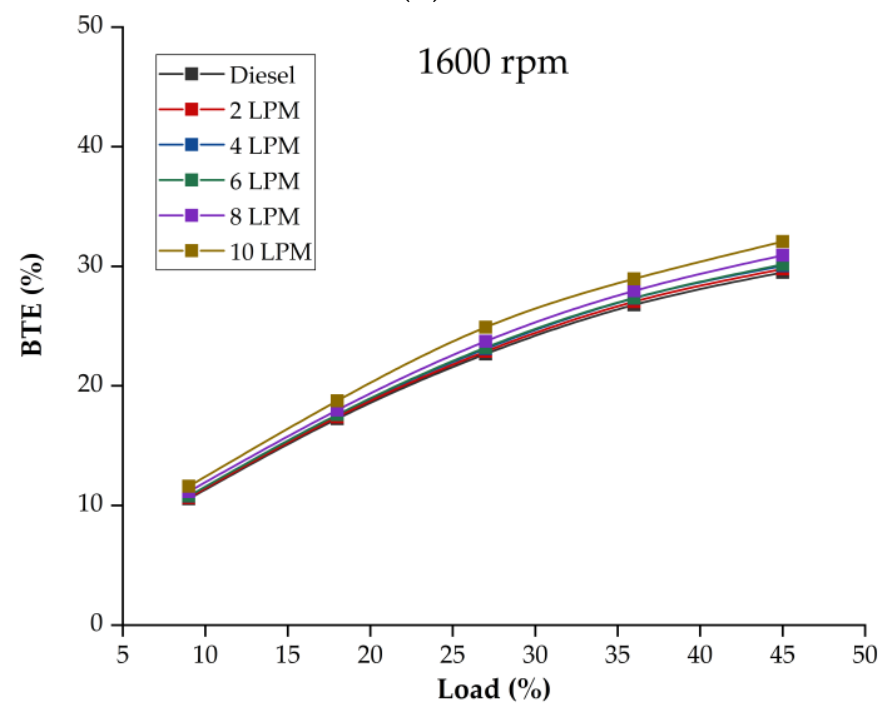

(d)

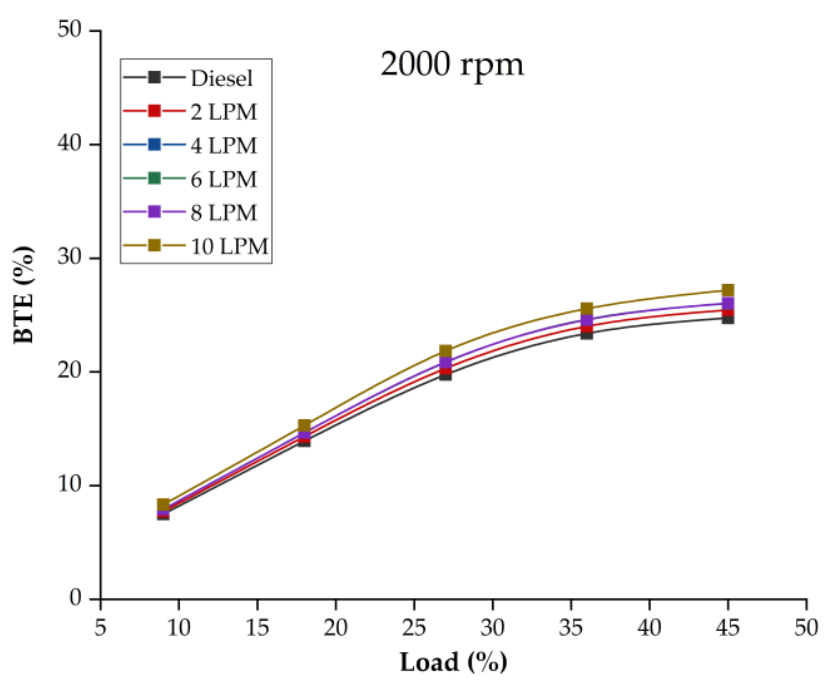

(f)

Figure 5. Cont. 


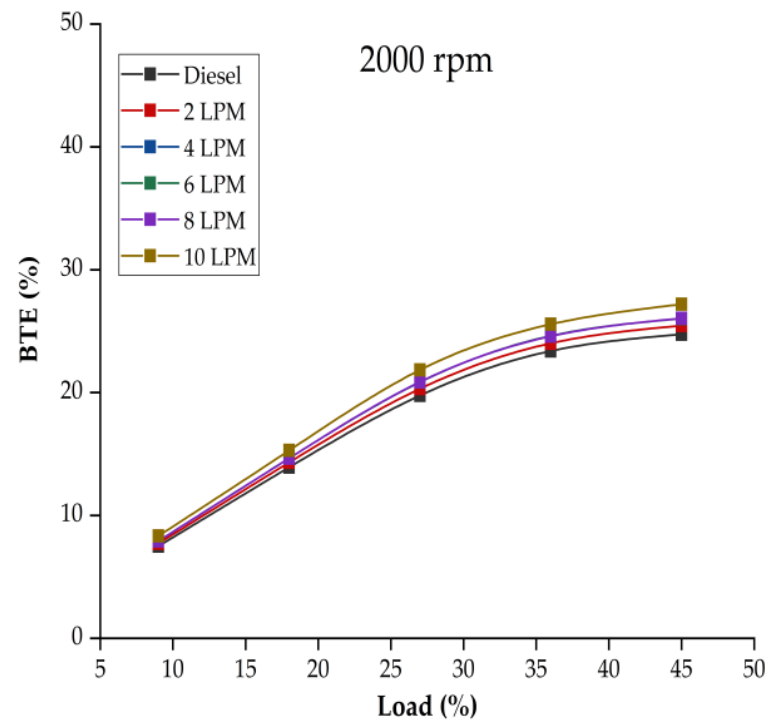

(g)

Figure 5. (a-g) Comparison of BTE for diesel-HHO blends in the speed range (1000-2200).

\section{ANN Application}

\subsection{Data Preprocessing}

Prior to the development of the model, the input data (speed, load, and flow rate) and output data (BSFC and BTE) were normalized between the $(0,1)$ range using Equations $(3)$ and (4). All the data were within 0 to 1 and no faulty data were detected.

$$
\begin{aligned}
\text { Input }^{\mathrm{N}} & =\frac{\text { input }-\min (\text { input })}{\max (\text { input })-\min (\text { input })} \\
\text { Output }^{\mathrm{N}} & =\frac{\text { Output }-\min (\text { output })}{\max (\text { output })-\min (\text { output })}
\end{aligned}
$$

\subsection{ANN Model}

ANN is chiefly a statistical model that stems from the very idea of the information processing system of the human brain [42]. Over the few decades, ANN models have been growing exceptionally more common, owing to their widespread use for analyzing, processing, system controls, and optimization applications. With similar popularity in other fields, it has also been expansively used in the automotive sector as performance parameters could be correctly estimated using it. Depending upon the complexity of data, the ANN could have many layers, but generically it is reported with three stages: input layer, hidden layer, and output layer [43,44]. Neurons are information carriers that act as a connecting medium between the three layers. The neurons are interlinked through communication links which are in turn connected with connection weights. The signals are transmitted to the neurons by connection weights.

In the current study, engine speed, $\mathrm{HHO}$ flow rate, and engine load were designated as input parameters for input layers while performance parameters (BSFC and BTE) were dedicated to the output layer. The number of experimental observations recorded were 210, which served as a dataset to the input layer of ANN. MATLAB NN Toolbox was used for developing the model, which randomly divided the input into three groups as training $(70 \%)$, validation $(15 \%)$, and testing $(15 \%)$. The network used in the hidden and output layers of the ANN model was a feedforward backpropagation network because of its valuable uses in the modelling of the system, signal processing of data with nonlinearities, and accuracy $[43,45]$. The Trainlm training function and mean square error (MSE) performance function were employed, which is generally a preferable combination 
for faultless predictions [46]. Owing to the magnitude of the data set and higher reported efficiency rates, the tansig transfer function was selected. For diminishing the errors, LEARNGDM learning function was used. The quantity of neurons in the hidden layer is central to the efficient prediction of the ANN model, as with too low a number the connection between input data and output predicted results could be feeble and the resultant model will be considered inappropriate [43,47]. Moreover, the criteria of ceasing the training on the escalation of validation error was used. Usually, the use of 10 neurons is widely reported in the literature and the same could also be considered for the present case. However, with such a rough guess, the results may often be misleading. Therefore, the optimum neurons were identified by iterations 5 points above and near 10 below which identified the use of 10 neurons for achieving desirable results. The trained ANN model may have an error in form overfitting, which is a considerable difference of error between the training and testing. Figure 6 shows the performance of ANN training for 1000 epochs, from which it could be arguably concluded that the test error is comparable to the training error and are converging at one value. Therefore, the ANN model is not over fitted. The attributes of the ANN models are epitomized in Table 4 and the detailed network structure of the ANN model is shown in Figure 7. The working of ANN for the current case is clarified by the process diagram shown in Figure 8. It encompasses three stages. Input parameters were introduced in the first stage, which were repetitively trained in the second stage for minimizing disparity, and checked for the desired results in the third stage.

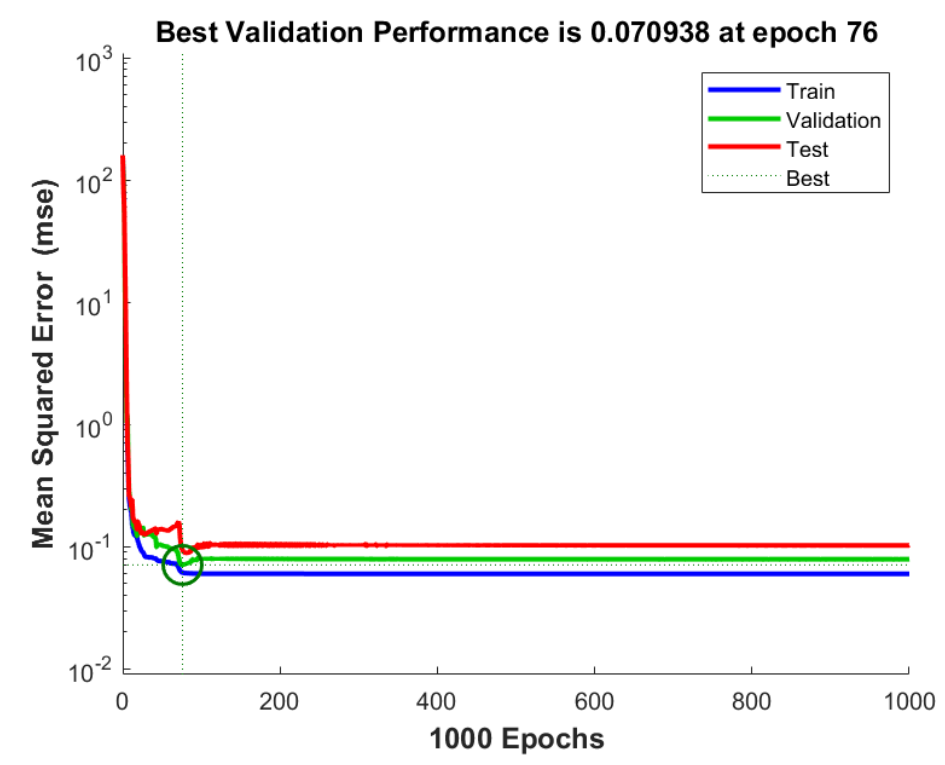

Figure 6. Performance validation of ANN.

Table 4. Attributes of the ANN model.

\begin{tabular}{cc}
\hline Attributes & Description \\
\hline Parameters & Three Inputs, Two Outputs, One hidden layer \\
Network Type & Feedforward backpropagation \\
Total number of data sets & 210 \\
Number of data sets for ANN training & 147 \\
Neuron in hidden layer & 10 \\
Data Division & $15 \%$ for validation, $15 \%$ for testing and $70 \%$ for training \\
\hline
\end{tabular}




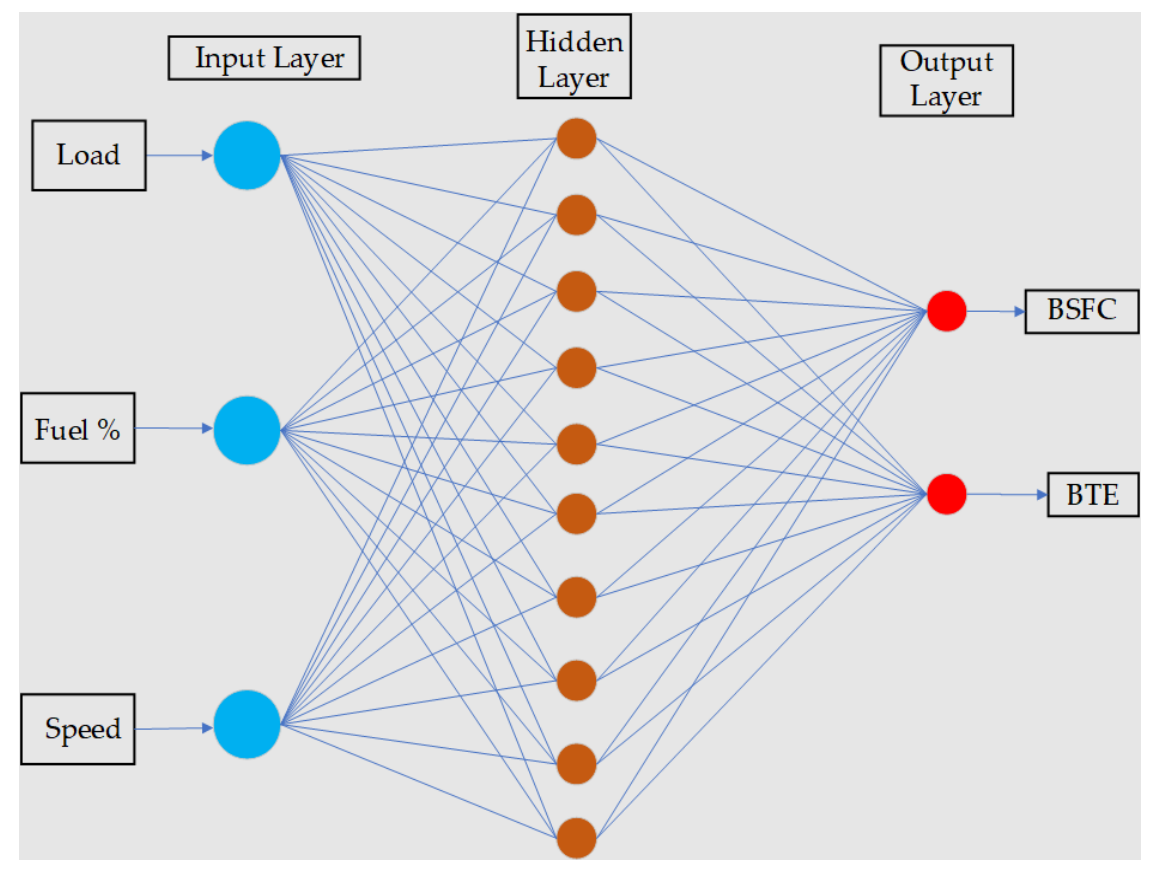

Figure 7. The ANN model.

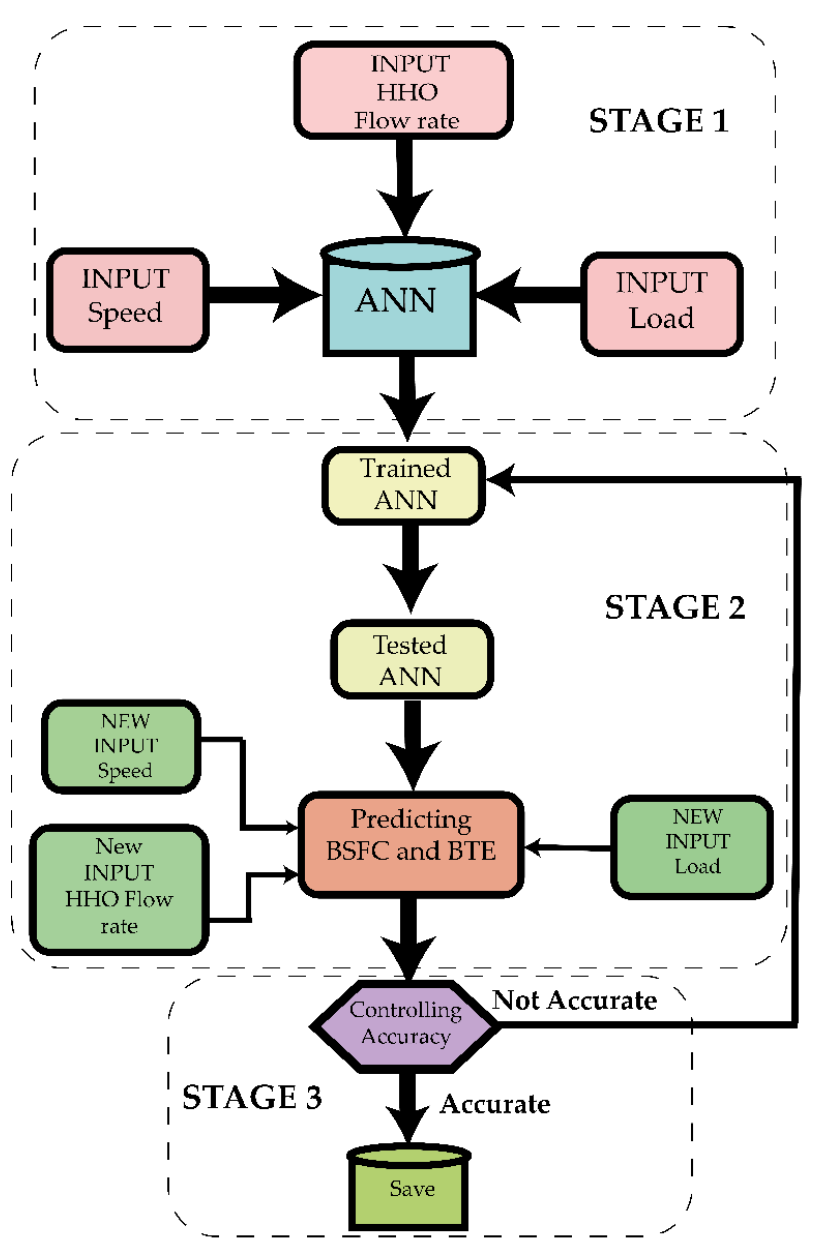

Figure 8. Working of ANN. 
The output results of the ANN model were tested using the statistical measures of mean relative error (MRE), Root mean square error (RMSE), and correlation coefficient $\left(\mathrm{R}^{2}\right)$, as defined in Equations (5)-(7):

$$
\begin{gathered}
\operatorname{MRE}(\%)=\frac{1}{n} \sum_{i=1}^{n}\left|100 \frac{t_{i}-p_{i}}{p_{i}}\right| \\
\operatorname{RMSE}=\sqrt{\frac{1}{n} \sum_{i=1}^{n}\left(p_{i}-o_{i}\right)^{2}} \\
R^{2}=1-\left(\frac{\sum_{i=1}^{n}\left(p_{i}-o_{i}\right)^{2}}{\sum_{i=1}^{n}\left(o_{i}\right)^{2}}\right)
\end{gathered}
$$

The best output results could be adjudicated by ensuing certain statistical ranges associated with the above formulas. In the current scenario, the ANN predicted outputs rendered appropriate based on two statistical indicators: (a) correlation coefficient (R) close to positive unity and (b) the MRE of input and output within the defined range of 1-3\%. In the case the predicted results failed to meet the demarcated criterion, the ANN model learning rate was varied.

\subsection{ANN Prediction Comparison and Discussion}

The prediction of performance characteristics of test engine fueled with diesel-HHO blends using the artificial intelligence approach proved exceptionally valuable. The overall regression graphs yielded by the ANN application are shown in Figure $9 \mathrm{a}-\mathrm{d}$. The results generated by the model were in line with the statistical criterion defined in the preceding sections. The correlation coefficients for the three stages of the developed neural network were found qua 0.99998 for training, 0.99988 for validation. 0.99978 for testing, and 0.99994 for training, testing, and validation as a whole. The correlation coefficients for all stages were precisely near to +1 , which demonstrates the well-matching of the experimental and ANN-predicted results.

The further analysis was initiated by evaluating the predicted and experiment results of BSFC and BTE on an individual basis as shown in Figure 10a,b. The correlation coefficient for BSFC returned a value of 0.99764. The MRE and RMSE accuracy-defining equations proved solid testimonies of BSFC model-generated results with values of $2.64 \%$ and $0.0122 \mathrm{~kg} / \mathrm{kWh}$. The statistical parameters showed that the prediction of the BSFC of a diesel engine operating on blended fuel using ANN has enough competence and efficiency. Similarly, the BTE-guessed values were significantly close to experimental values shown with R, MRE, and RMSE values of $0.99902,1.91 \%$, and $0.2768 \%$. The BTE ANN model proved remarkable in the prediction of performance parameters.

The comprehensive comparison of two data sets, experimental and predicted, for each observation of parameters (BSFC and BTE) is shown in Figure 11a,b. The plotted line graphs depict the overlapping data points for most of the test runs, signaling the negligible deviations. From 210 observations, there are only a few sets for which the predicted values were seen escalating on either extreme, but collectively, they could merely be ignored due to an inconsequential effect. The in-depth analysis of the obtained statistical parameters unequivocally advocates that the ANN prediction model is suitable for performance parameters. 
(a)
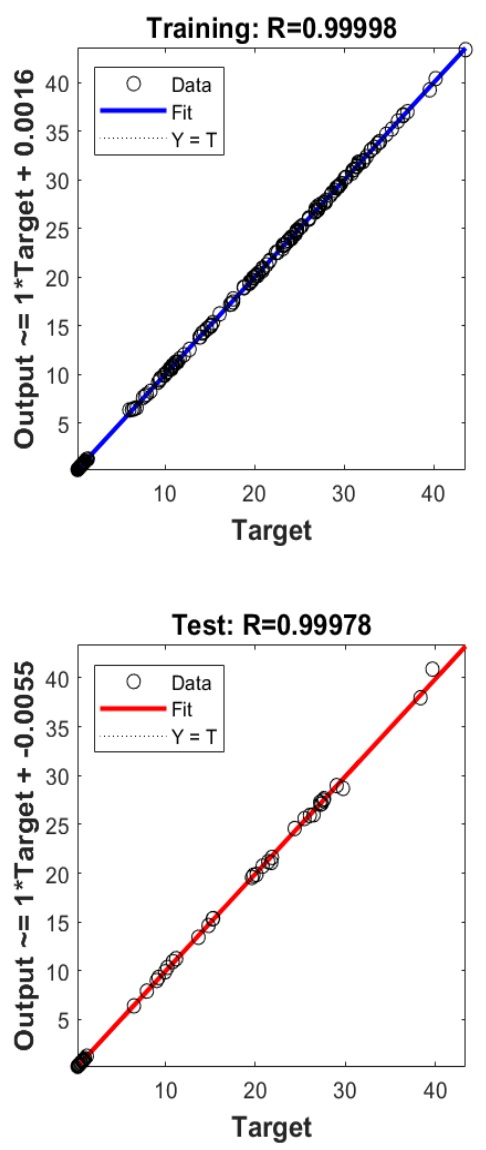

(c) (b)
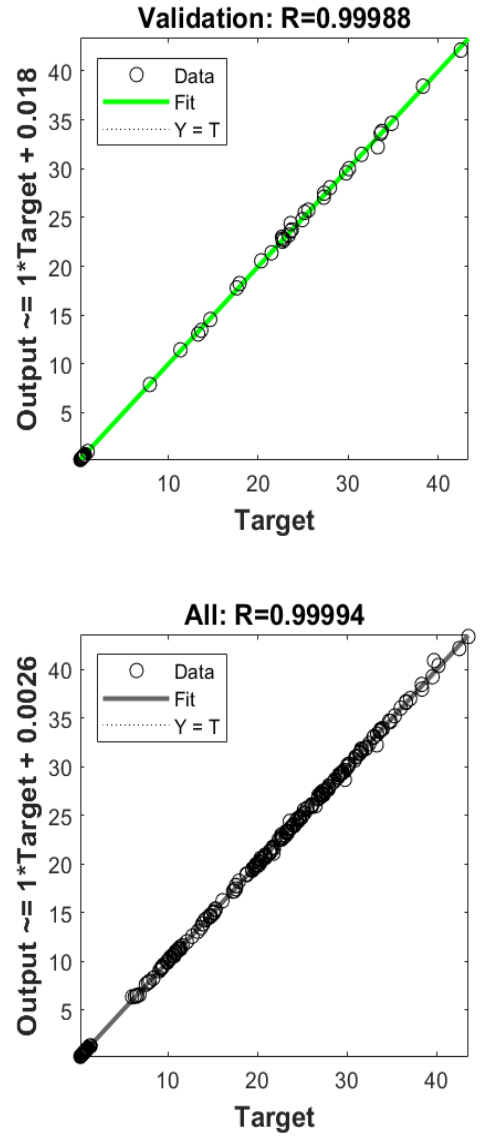

(d)

Figure 9. (a) Training, (b) validation, (c) testing, and (d) overall correlation coefficients.

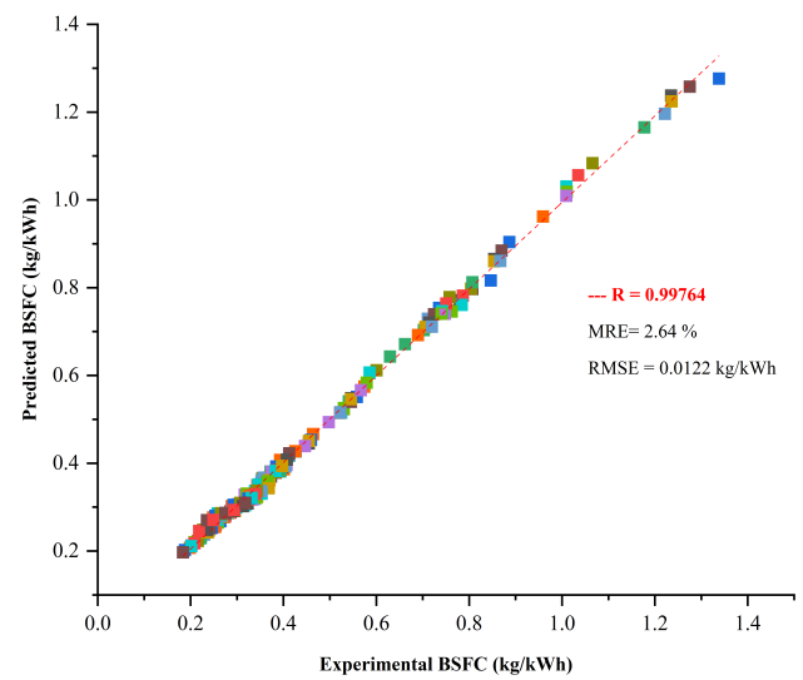

(a)

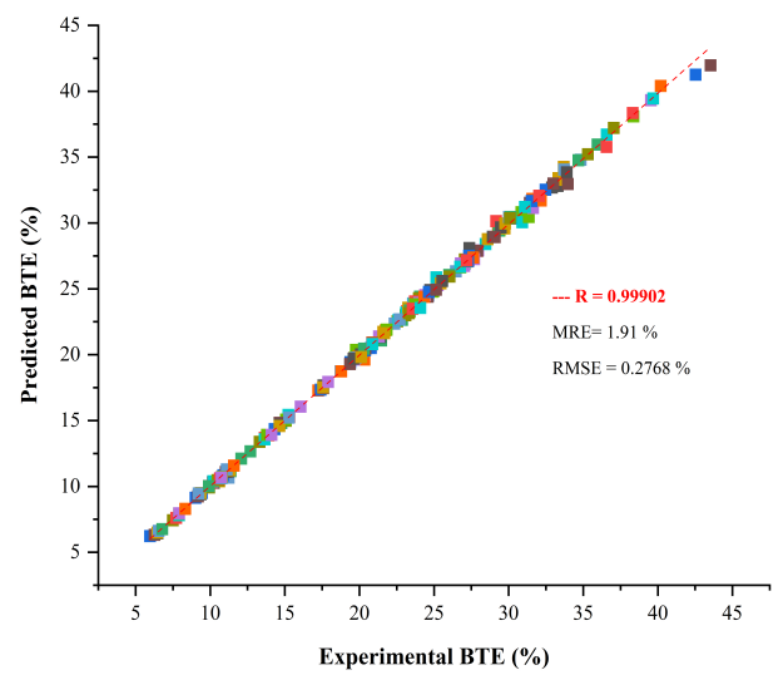

(b)

Figure 10. Comparison of predicted results with experimental results for (a) BSFC and (b) BTE. 


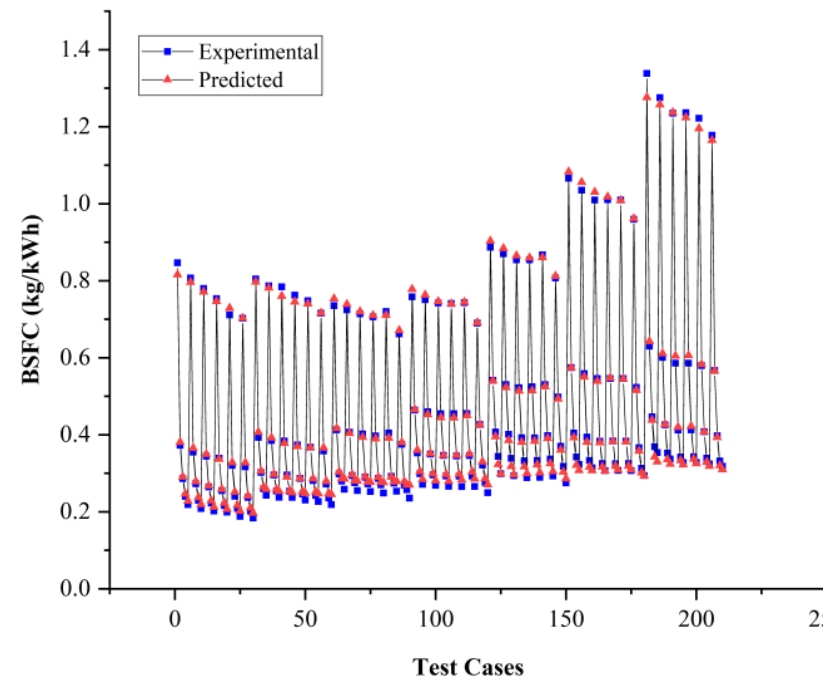

(a)

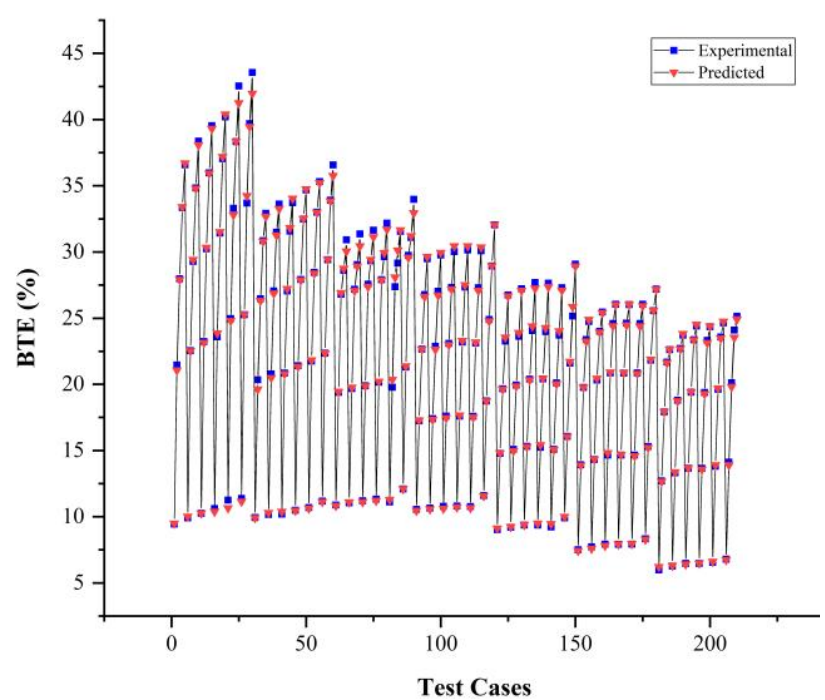

(b)

Figure 11. Comparison of experimental and predicted values for (a) BSFC and (b) BTE.

\section{RSM-Based Optimization}

Optimization of any process aims at achieving the maximum output by manipulating the controlled variables. In any optimization technique, numerical constraints are typically introduced for either maximizing or minimizing the response variables. Several available optimization techniques could admirably define the optimized parameters within the provided range. Response surface methodology (RSM) is a well-known statistical technique employed for the optimization of involved parameters using experimentally extracted data for solving multiple simultaneous equations. Over the years, the RSM has been seen extensively used in the engineering sector owing to its accurate prediction of response(s) influenced by multiple discrete factors. In the current optimization study, the BSFC and $\mathrm{BTE}$ of the test engine were nominated as response variables. The goal was to maximize BTE and minimize BSFC. The RSM design factors considered for optimization of diesel engine performance attributes were engine speed (rpm), HHO flow rate (LPM), and load of the engine (\%). Design Expert 11 was used for creating the model and response surfaces. A multilevel design for a pre-defined experimental strategy was developed using historical data feature. The model defining parameters, listed in Table 5, were three numeric factors, seven levels of speed, six levels of HHO blend, and five levels of engine load.

Table 5. Factors and levels.

\begin{tabular}{cccccccccc}
\hline Factors & Units & Levels & L [1] & L [2] & L [3] & L [4] & L [5] & L [6] & L [7] \\
\hline Speed & Rpm & 7 & 1000 & 1200 & 1400 & 1600 & 1800 & 2000 & 2200 \\
Flow rate & LPM & 6 & 0 & 2 & 4 & 6 & 8 & 10 & - \\
Load & $\%$ & 5 & 9 & 18 & 27 & 36 & 45 & - & - \\
\hline
\end{tabular}

\subsection{Selection of an Empirical Model}

The fit summaries of BSFC and BTE are listed in Tables 6 and 7. Generally, the selection of the appropriate model is governed by (a) $p$-value (b) predicted $\mathrm{R}^{2}$ and (c) reasonable agreement between predicted and adjusted $R^{2}$ [48]. Based on the mentioned assessing parameters, the first two models (linear and 2FI) had small values of $R^{2}$. However, the quadratic model had the signs of best fit, owing to $p<0.0001$ and $R^{2}$ significantly close to 1 . Recent studies have also shown that the engine combustion process is complex and therefore could be aptly described with a quadratic model [49]. Thus, referring to the deduced observations and published literature, the quadratic model was designated for optimization purposes. 
Table 6. BSFC fit summary.

\begin{tabular}{cccc}
\hline Source & $p$-Value & Adjusted $\mathbf{R}^{2}$ & ${\text { Predicted } \mathbf{R}^{2}}^{2}$ \\
\hline Linear & $<0.05$ & 0.7224 & 0.7135 \\
2FI & $<0.05$ & 0.7482 & 0.7316 \\
Quadratic & $<0.05$ & 0.9939 & 0.9922 \\
\hline
\end{tabular}

Table 7. BTE fit summary.

\begin{tabular}{cccc}
\hline Source & $\boldsymbol{p}$-Value & ${\text { Adjusted } \mathbf{R}^{2}}$ & Predicted $^{2}$ \\
\hline Linear & $<0.05$ & 0.9187 & 0.9161 \\
2FI & $<0.05$ & 0.9368 & 0.9335 \\
Quadratic & $<0.0001$ & 0.9940 & 0.9958 \\
\hline
\end{tabular}

\subsection{Analysis of Variance and Predicting Equations}

Analysis of variance (ANOVA) is a statistical tool used for assessing the statistical significance of the model, individual terms, and interactions. It provides a detailed understanding of the regression model as the interactions between the factors and the responses can be explicitly comprehended. Tables 8 and 9 provide the ANOVA for the quadratic models of BSFC and BTE. The model F values of 383.56 and 1298.30 for BSFC and BTE imply that models are significant. The model terms have been abbreviated as A-Speed, $\mathrm{B}-\mathrm{HHO}$ flow rate, and C-load. The $p$ values less than 0.0500 indicate the significance of model terms. In the case of $\mathrm{BSFC}, \mathrm{A}, \mathrm{B}, \mathrm{C}, \mathrm{AC}, \mathrm{BC}, \mathrm{A}^{2}$, and $\mathrm{C}^{2}$ are significant model terms. The $p$ values of the terms $\mathrm{AB}, \mathrm{BC}$, and $\mathrm{C}^{2}$ indicate the model terms that are insignificant. The accuracy of the models under consideration has been verified using the diagnostic predicted vs actual and residual vs run plots as shown in Figure 12a-d. Figure 12a,b demonstrates that for BSFC and BTE, the RSM predicted values are in close agreement with the ANN values, indicated by the colored data point falling on the linear inclined line. Similarly, the deviation of RSM and actual (ANN) values were in the narrow residual range of $[-3.7428,+3.7428]$, as depicted in Figure 12c,d. The even distribution atop and below the reference axis, for both the cases, signals the statistical significance of BSFC and BTE RSM models. The response surfaces of BSFC and BTE variation with engine speed, $\mathrm{HHO}$ percentage, and engine load are shown in Figures 13 and 14 respectively. It is visible that all the design factors had a significant effect on responses. The dark and light dots on the response surfaces shows the design points above and below predicted values, respectively.

Table 8. ANOVA for BSFC.

\begin{tabular}{cccccc}
\hline Source & $\begin{array}{c}\text { Sum of } \\
\text { Squares }\end{array}$ & Df & $\begin{array}{c}\text { Mean } \\
\text { Square }\end{array}$ & F-Value & $p$-Value \\
\hline Model & 11.51 & 9 & 1.28 & 383.56 & $<0.0001$ \\
A-Speed & 1.06 & 1 & 1.06 & 317.29 & $<0.0001$ \\
B-Flow rate & 0.0357 & 1 & 0.0357 & 10.71 & $<0.0001$ \\
C-Load & 7.75 & 1 & 7.75 & 2324.75 & $<0.0001$ \\
AB & 0.0000 & 1 & 0.0000 & 0.0032 & 0.9551 \\
AC & 0.3384 & 1 & 0.3384 & 101.49 & $<0.0001$ \\
BC & 0.0156 & 1 & 0.0156 & 4.68 & 0.0317 \\
A $^{2}$ & 0.0606 & 1 & 0.0606 & 18.18 & $<0.0001$ \\
B $^{2}$ & 0.0001 & 1 & 0.0001 & 0.0240 & 0.8771 \\
C $^{2}$ & 2.25 & 1 & 2.25 & 674.88 & $<0.0001$ \\
\hline
\end{tabular}


Table 9. ANOVA for BTE.

\begin{tabular}{cccccc}
\hline Source & $\begin{array}{c}\text { Sum of } \\
\text { Squares }\end{array}$ & Df & $\begin{array}{c}\text { Mean } \\
\text { Square }\end{array}$ & F-Value & $p$-Value \\
\hline Model & 15229.95 & 9 & 1692.22 & 1298.30 & $<0.0001$ \\
A-Speed & 2724.04 & 1 & 2724.04 & 2089.93 & $<0.0001$ \\
B-Flow rate & 110.22 & 1 & 110.22 & 84.56 & $<0.0001$ \\
C-Load & 11414.41 & 1 & 11414.41 & 8757.34 & $<0.0001$ \\
AB & 19.49 & 1 & 19.49 & 14.95 & 0.0001 \\
AC & 262.83 & 1 & 262.83 & 201.65 & $<0.0001$ \\
BC & 9.03 & 1 & 9.03 & 6.93 & 0.0091 \\
A $^{2}$ & 31.18 & 1 & 31.18 & 23.92 & $<0.0001$ \\
B $^{2}$ & 0.3481 & 1 & 0.3481 & 0.2671 & 0.6059 \\
C $^{2}$ & 658.42 & 1 & 658.42 & 505.15 & $<0.0001$ \\
\hline
\end{tabular}

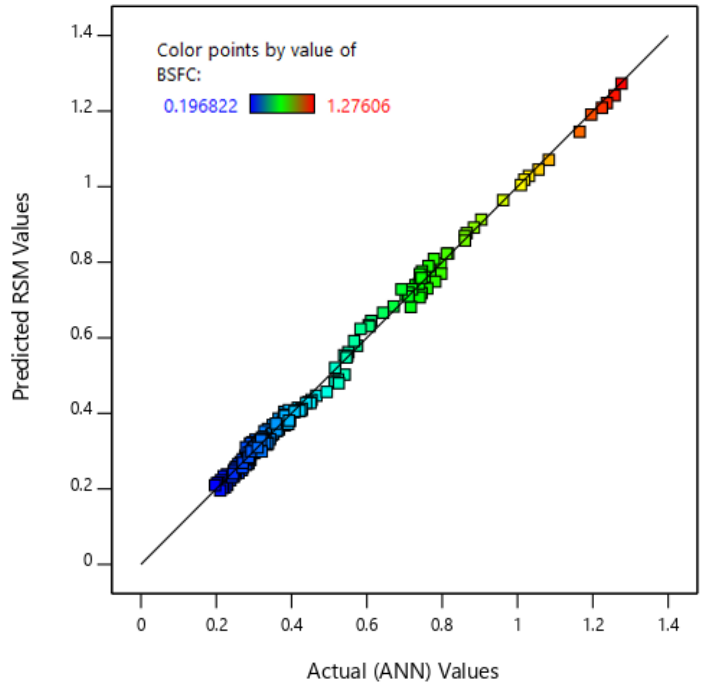

(a)

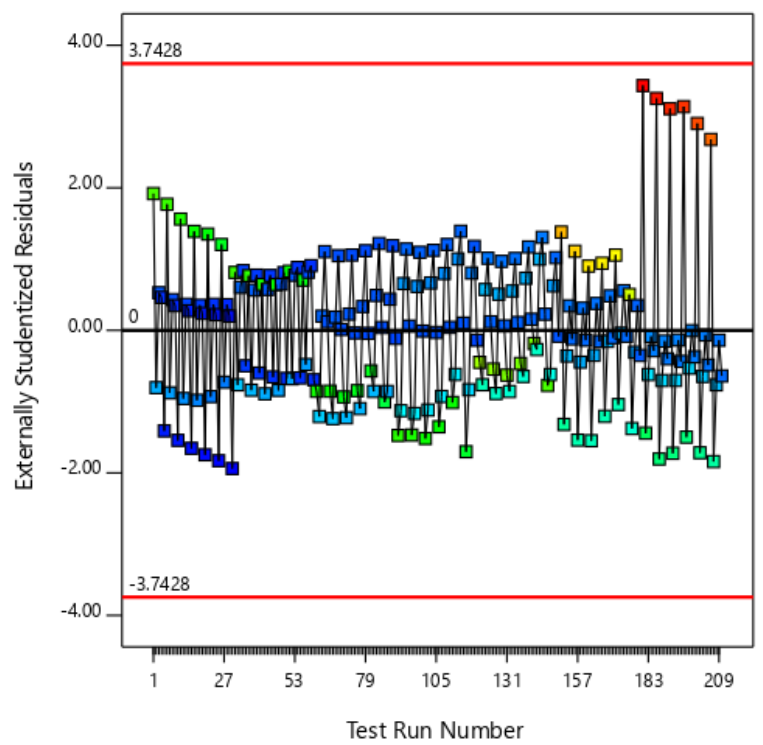

(c)

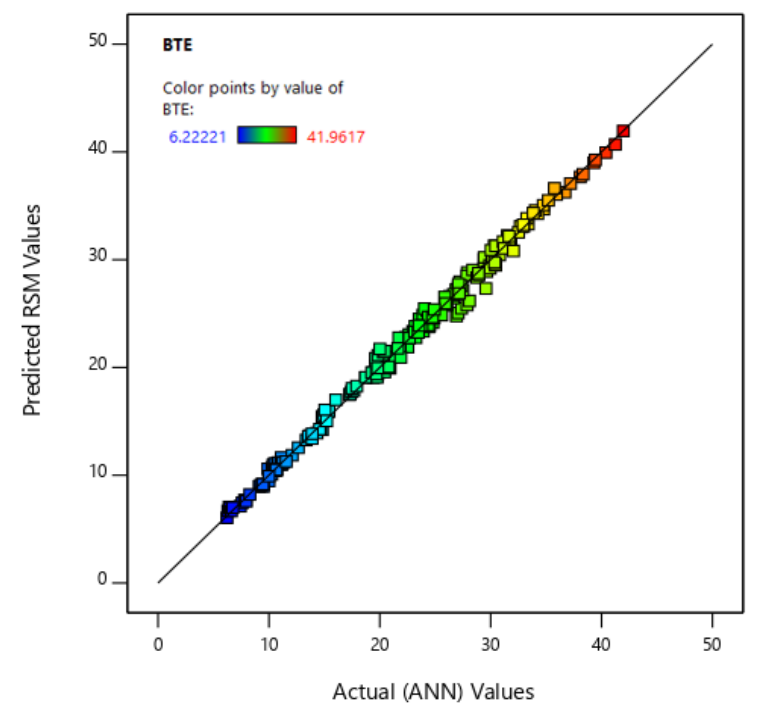

(b)

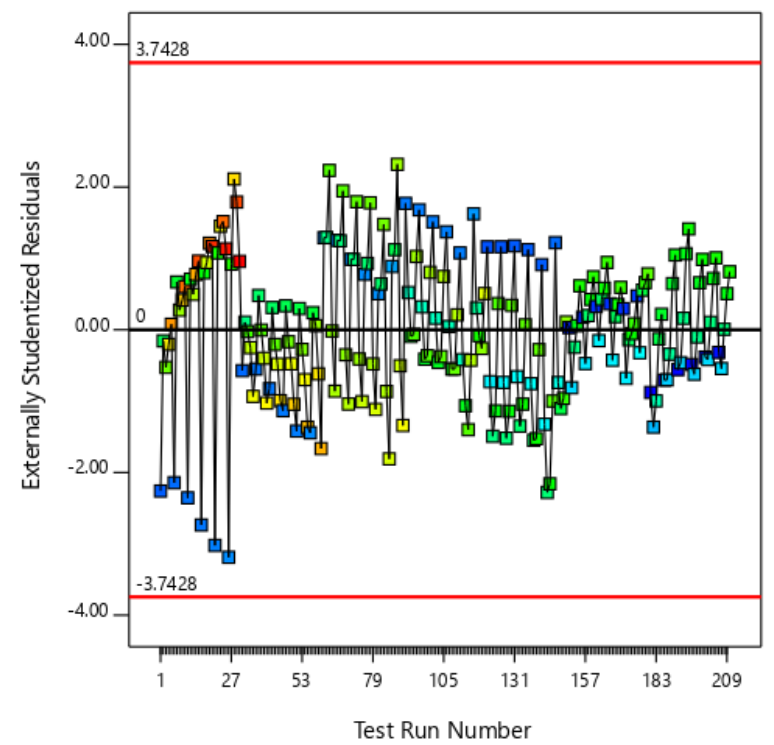

(d)

Figure 12. (a-d) Predicted vs actual graph for (a) BSFC and (b) BTE and residual vs. run graphs for (a) BSFC and BTE RSM models. 
Second-order regression equations relating the input parameters and responses for estimation of performance are given by coded Equations (8) and (9). The coded alphabets A, B, and C correspond to the study design factors: speed, HHO flow rate, and load, respectively. By using the corresponding values of speed, flow rates, and engine load, in the regression equations, the values of BSFC and BTE could be accurately predicted.

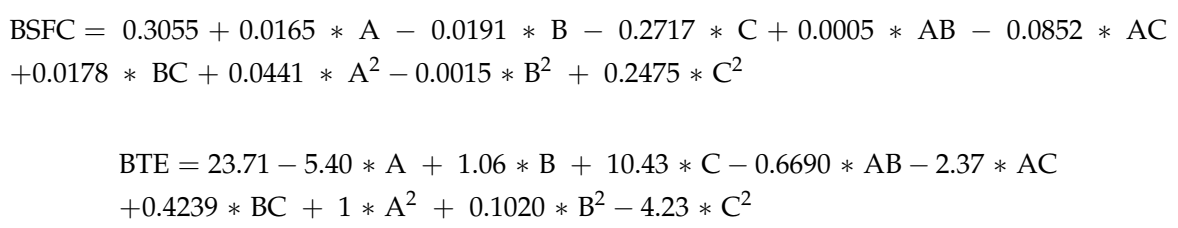

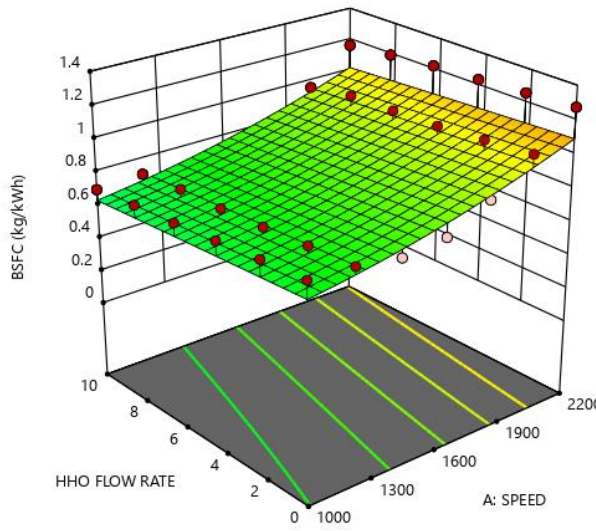

(a)

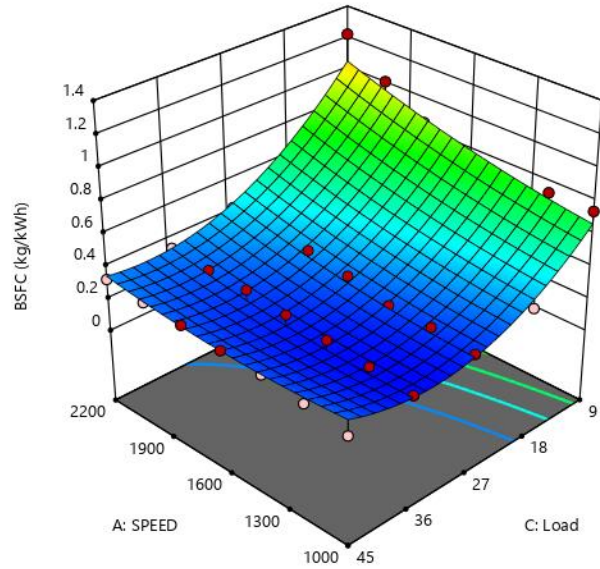

(b)

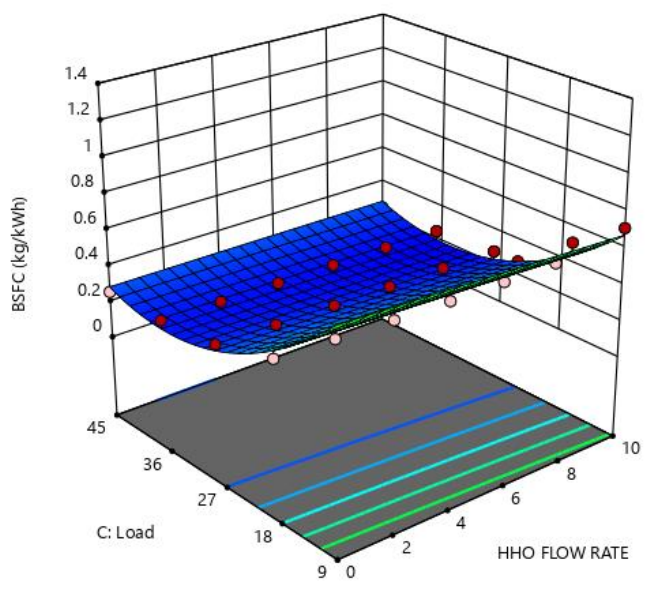

(c)

Figure 13. Response surfaces variation of BSFC with (a) flow rate and speed, (b) speed and load, and (c) load and flow rate. 


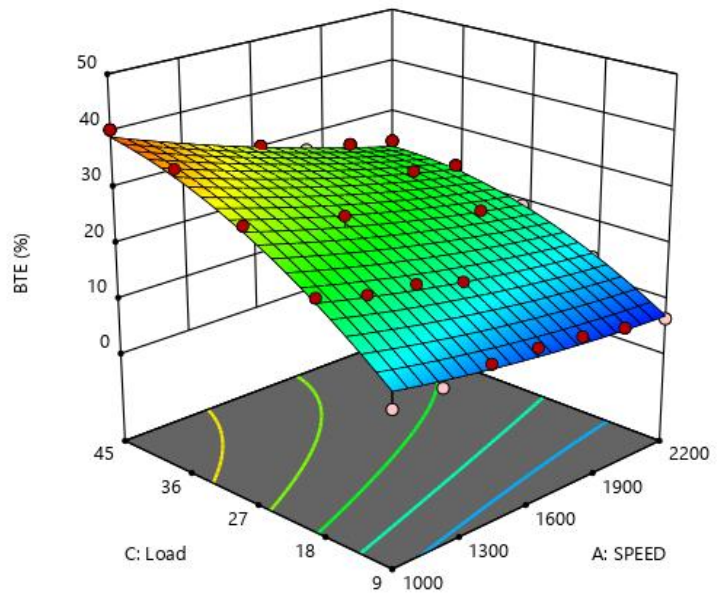

(a)

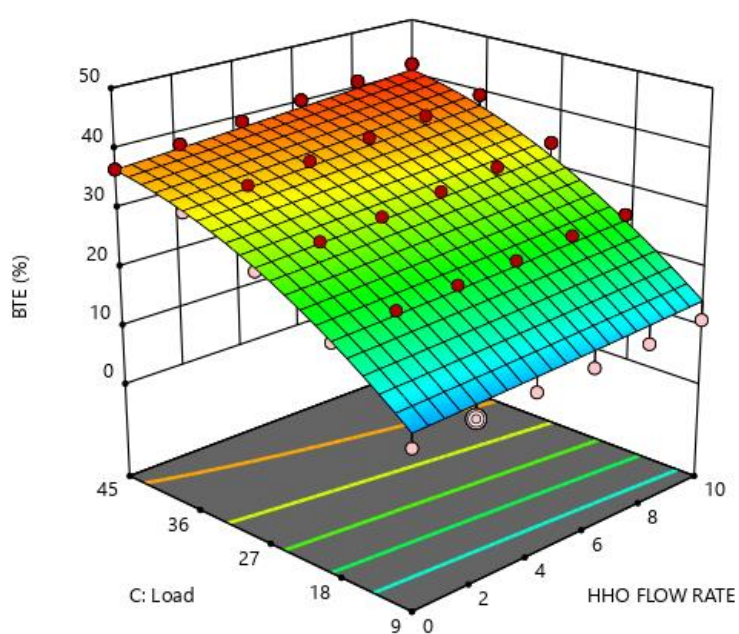

(b)

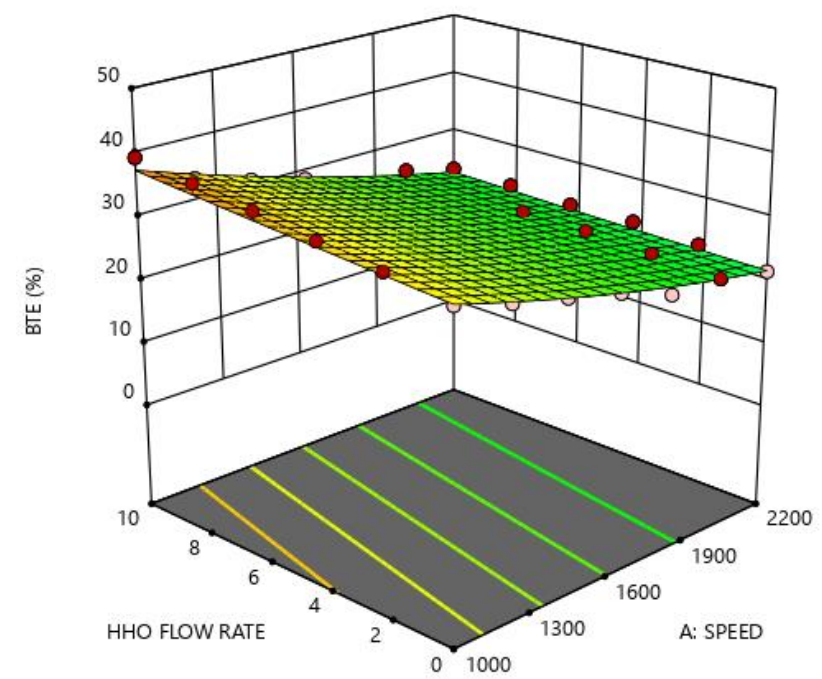

(c)

Figure 14. Response surfaces variation of BTE with (a) load and speed, (b) load and HHO, and (c) flow rate and speed.

\subsection{Optimization Results and Validation}

In the current study, objective of RSM was to recognize the engine optimum working conditions. The speed, flow rate, and load were design factors, and ANN estimated values of BSFC and BTE were the outputs (responses). The design expert optimization feature demands optimal constraints to be defined for the factors and responses. Table 10 illustrates the defined constraints and setup for optimization. The goal was to optimize the engine with targets of minimizing BSFC and maximizing BTE while keeping the within range criterion for study factors.

Table 10. Optimization setup.

\begin{tabular}{|c|c|c|c|c|c|c|}
\hline Factors & $\begin{array}{c}\text { Desired } \\
\text { Goal }\end{array}$ & $\begin{array}{l}\text { Lower } \\
\text { Value }\end{array}$ & $\begin{array}{l}\text { Upper } \\
\text { Value }\end{array}$ & $\begin{array}{c}\text { Lower } \\
\text { Weight }\end{array}$ & $\begin{array}{c}\text { Upper } \\
\text { Weight }\end{array}$ & Importance \\
\hline A: Speed (rpm) & Is in range & 1000 & 2200 & 1 & 1 & 3 \\
\hline B: HHO Flow rate (LPM) & Is in range & 0 & 10 & 1 & 1 & 3 \\
\hline C: Load (\%) & Is in range & 0 & 45 & 1 & 1 & 3 \\
\hline BSFC (kg/kWh) & Minimum & 0.196822 & 1.27606 & 1 & 1 & 3 \\
\hline BTE $(\%)$ & Maximum & 6.22221 & 41.9617 & 1 & 1 & 3 \\
\hline
\end{tabular}


The best operating parameters for engine performance came out to be $1000 \mathrm{rpm}, 10 \mathrm{~L}$ per minute flow rate of $\mathrm{HHO}$, and $45 \%$ engine load. The performance parameters against these optimal values of design factors are $0.301 \mathrm{~kg} / \mathrm{kWh}$ BSFC and $40.939 \%$ of BTE. The composite desirability (D) is a unitless number that lies within the range of zero to one. It is a measure of favorability to which input defining factors optimize the objectives as a whole. The closer the value to the 1 , the more favorable the optimization. In the current study, the composite desirability was detected to be 0.971 . A value sufficiently close to 1 indicates that the employed RSM models are highly efficient and could be used to predict the optimum design factors for the efficient performance of the diesel engine.

The RSM-optimized results could be easily validated by conducting the experimental runs. Therefore, experimental observations of BSFC and BTE were recorded corresponding to optimized values of speed, flow rates, and loads, and the comparison is shown in Figure 15a,b. The experimental observation returned a value of BSFC $5.64 \%$, less as compared with an optimized parameter. Similarly, the optimum value for brake thermal efficiency was $6.15 \%$ lower in comparison with experimental observation. With sufficient agreement between optimized and experimental observations as the basis, the RSM is viable and practically implementable.

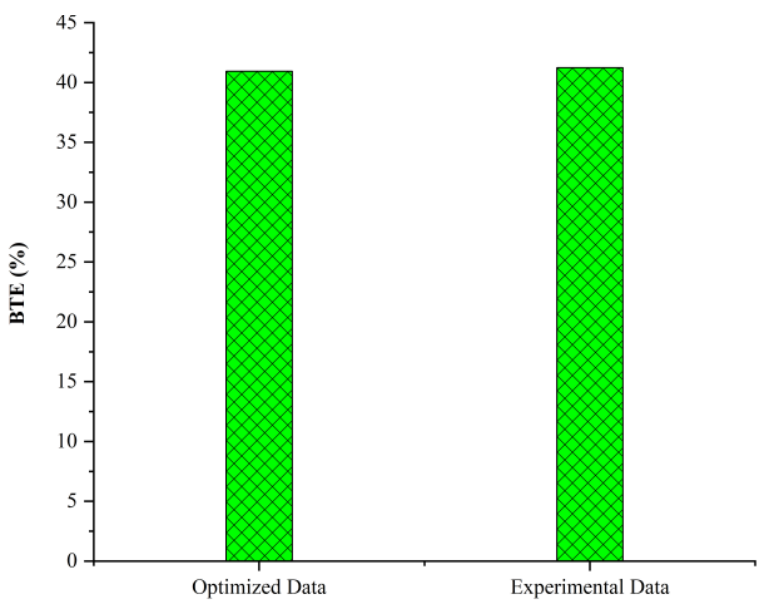

(a)

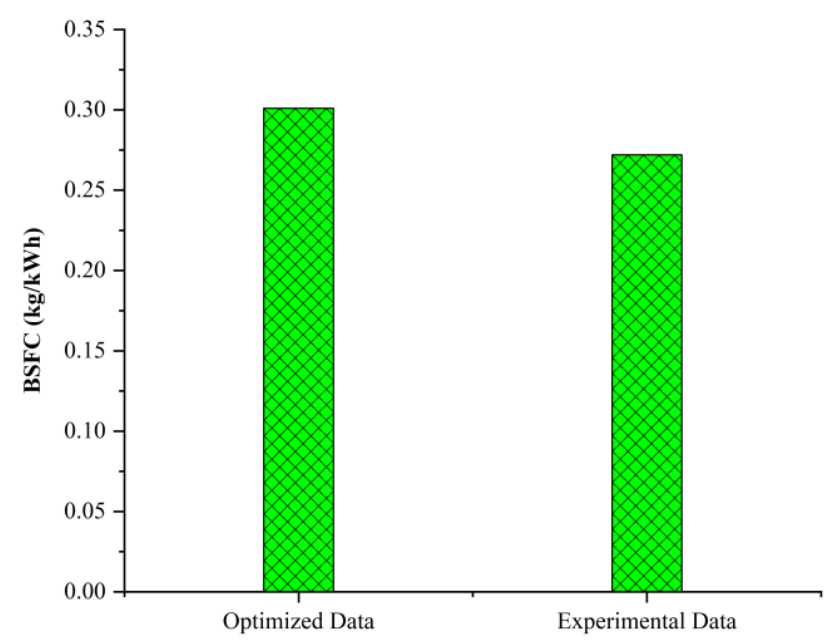

(b)

Figure 15. Comparison of optimized and experimental results for (a) BSFC and (b) BTE.

\section{Comparison of ANN and RSM Models}

The artificial intelligence and statistically based predicting models of BSFC and BTE seemingly have alike reliability and efficiency. However, due to the generic association of methods root task to the same domains, the comparative assessment of the two will be an ideal approach. The detailed comparison of MRE and RMSE of ANN and RSM models is shown in Table 11. The statistical comparison discloses that the ANN models of BSFC and BTE have a better ability to efficiently predict parameters of an engine due to lower MRE and RMSE. ANN and RSM returned MRE values of $1.91 \%$ and $2.26 \%$ for BTE and $2.64 \%$ and $2.94 \%$ for BSFC, respectively. Similarly, the RMSE given by ANN and RSM for BSFC were 0.012 and $0.088 \mathrm{~kg} / \mathrm{kWh}$, respectively. The comparison vouched for ANN's efficiency and reliability as the statistical parameters (MRE and RMSE) of both parameters were less than its competitor. 
Table 11. ANN and RSM comparison.

\begin{tabular}{cccc}
\hline Models & Parameters & MRE\% & RMSE \\
\hline \multirow{2}{*}{ ANN } & BTE $(\%)$ & 1.91 & 0.27 \\
& BSFC $(\mathrm{kg} / \mathrm{kWh})$ & 2.64 & 0.012 \\
\hline \multirow{2}{*}{ RSM } & BTE $(\%)$ & 2.26 & 0.41 \\
& BSFC $(\mathrm{kg} / \mathrm{kWh})$ & 2.94 & 0.088 \\
\hline
\end{tabular}

\section{Conclusions}

This study evaluated the use of oxyhydrogen gas with diesel at different flow rates in a CI engine. ANN and RSM tools were collectively used for performance prediction and optimization. The results could be summarized as:

- 10 LPM HHO with diesel was found to be most fuel efficient among all test fuels.

- HHO addition to the diesel improved BTE for all flow rates. Pure diesel showed the least BTE among all combinations of fuels.

- The correlation coefficients of training, testing, and validation of the ANN model came out to be $0.99998,0.99988$, and 0.99978 respectively. Moreover, MRE values were in the range of $1-3 \%$.

- $\quad$ RSM identified all the study factors as statistically significant owing to $p$ values less than 0.005 .

- Optimum operating conditions for engine were $1000 \mathrm{rpm}, 10 \mathrm{LPM} \mathrm{HHO}$, and 45\% loading condition.

- Composite desirability of 0.971 for multi-response optimization indicated the appropriate optimization setting.

- $\quad$ The experimental BSFC and BTE differed by $5.64 \%$ and $6.15 \%$ from RSM-optimized values.

- The ANN model proved better than RSM due to low RMSE and MRE values.

Thus, the addition of $\mathrm{HHO}$ to diesel proved highly valuable for improved performance. The statistical assessment tools (R, MRE, and RMSE) revealed that the performance could be accurately predicted by ANN and RSM models. Conclusively, the HHO enrichment to the diesel is desirable for better performance and could be optimized using Artificial Intelligence and statistical methods.

The authors aim at conducting studies to investigate the effect of $\mathrm{HHO}$ with a stepwise increment beyond $45 \%$ loading condition along with the collective and individual ANN modelling for outputs with different algorithms and training functions.

Author Contributions: Conceptualization, M.U., A.A.Z. and U.B.; methodology, M.U., H.H. and F.R.; software, R.B., M.H.S. and U.B.; validation, M.A.K., M.A.M. and A.A.Z.; formal analysis, M.A.K. and M.A.M.; investigation, H.H. and M.U.; writing-original draft preparation, M.U. and M.H.S.; writing-review and editing, F.R., R.B., M.I. and M.E.M.S.; supervision, M.U.; project administration, M.A.M.; funding acquisition, M.A.K. All authors have read and agreed to the published version of the manuscript.

Funding: The authors would like to thank the Faculty of Engineering at the University of Malaya, Malaysia for their support through the research grant no GPF018A-2019.

Institutional Review Board Statement: Not applicable.

Informed Consent Statement: Not applicable.

Data Availability Statement: Not applicable.

Conflicts of Interest: The authors declare no conflict of interest.

\section{References}

1. Usman, M.; Jamil, M.K.; Riaz, F.; Hussain, H.; Hussain, G.; Shah, M.H.; Qyyum, M.A.; Salman, C.A.; Lee, M. Refining and Reuse of Waste Lube Oil in SI Engines: A Novel Approach for a Sustainable Environment. Energies 2021, 14, 2937. [CrossRef]

2. Archer, D. Fate of fossil fuel $\mathrm{CO}_{2}$ in geologic time. J. Geophys. Res. Ocean. 2005, 110. [CrossRef] 
3. Hussain, F.; Soudagar, M.E.M.; Afzal, A.; Mujtaba, M.; Fattah, I.; Naik, B.; Mulla, M.H.; Badruddin, I.A.; Khan, T.; Raju, V.D. Enhancement in Combustion, Performance, and Emission Characteristics of a Diesel Engine Fueled with Ce-ZnO Nanoparticle Additive Added to Soybean Biodiesel Blends. Energies 2020, 13, 4578. [CrossRef]

4. Mujtaba, M.; Kalam, M.; Masjuki, H.; Gul, M.; Soudagar, M.E.M.; Ong, H.C.; Ahmed, W.; Atabani, A.; Razzaq, L.; Yusoff, M. Comparative study of nanoparticles and alcoholic fuel additives-biodiesel-diesel blend for performance and emission improvements. Fuel 2020, 279, 118434. [CrossRef]

5. Mujtaba, M.; Masjuki, H.; Kalam, M.; Noor, F.; Farooq, M.; Ong, H.C.; Gul, M.; Soudagar, M.E.M.; Bashir, S.; Rizwanul Fattah, I. Effect of Additivized Biodiesel Blends on Diesel Engine Performance, Emission, Tribological Characteristics, and Lubricant Tribology. Energies 2020, 13, 3375. [CrossRef]

6. Soudagar, M.E.M.; Banapurmath, N.R.; Afzal, A.; Hossain, N.; Abbas, M.M.; Haniffa, M.A.C.M.; Naik, B.; Ahmed, W.; Nizamuddin, S.; Mubarak, N.M. Study of diesel engine characteristics by adding nanosized zinc oxide and diethyl ether additives in Mahua biodiesel-diesel fuel blend. Sci. Rep. 2020, 10, 15326. [CrossRef]

7. Mujtaba, M.A.; Muk Cho, H.; Masjuki, H.H.; Kalam, M.A.; Farooq, M.; Soudagar, M.E.M.; Gul, M.; Afzal, A.; Ahmed, W.; Raza, A.; et al. Effect of primary and secondary alcohols as oxygenated additives on the performance and emission characteristics of diesel engine. Energy Rep. 2021, 7, 1116-1124. [CrossRef]

8. Kumar, M.S.; Ramesh, A.; Nagalingam, B. Use of hydrogen to enhance the performance of a vegetable oil fuelled compression ignition engine. Int. J. Hydrog. Energy 2003, 28, 1143-1154.

9. Soudagar, M.E.M.; Afzal, A.; Safaei, M.R.; Manokar, A.M.; El-Seesy, A.I.; Mujtaba, M.A.; Samuel, O.D.; Badruddin, I.A.; Ahmed, W.; Shahapurkar, K.; et al. Investigation on the effect of cottonseed oil blended with different percentages of octanol and suspended MWCNT nanoparticles on diesel engine characteristics. J. Therm. Anal. Calorim. 2020. [CrossRef]

10. Khan, H.; Soudagar, M.E.M.; Kumar, R.H.; Safaei, M.R.; Farooq, M.; Khidmatgar, A.; Banapurmath, N.R.; Farade, R.A.; Abbas, M.M.; Afzal, A. Effect of nano-graphene oxide and n-butanol fuel additives blended with diesel—Nigella sativa biodiesel fuel emulsion on diesel engine characteristics. Symmetry 2020, 12, 961. [CrossRef]

11. Takaishi, T.; Numata, A.; Nakano, R.; Sakaguchi, K. Approach to high efficiency diesel and gas engines. Mitsubishi Heavy Ind. Rev. 2008, 45, 21-24.

12. Lanjewar, P.B.; Rao, R.; Kale, A. Assessment of alternative fuels for transportation using a hybrid graph theory and analytic hierarchy process method. Fuel 2015, 154, 9-16. [CrossRef]

13. Mujtaba, M.; Cho, H.M.; Masjuki, H.; Kalam, M.; Ong, H.; Gul, M.; Harith, M.; Yusoff, M. Critical review on sesame seed oil and its methyl ester on cold flow and oxidation stability. Energy Rep. 2020, 6, 40-54. [CrossRef]

14. S Gavhane, R.; M Kate, A.; Pawar, A.; Safaei, M.R.; M Soudagar, M.E.; Mujtaba Abbas, M.; Muhammad Ali, H.; R Banapurmath, N.; Goodarzi, M.; Badruddin, I.A. Effect of Zinc Oxide Nano-Additives and Soybean Biodiesel at Varying Loads and Compression Ratios on VCR Diesel Engine Characteristics. Symmetry 2020, 12, 1042. [CrossRef]

15. Soudagar, M.E.M.; Mujtaba, M.A.; Safaei, M.R.; Afzal, A.; V, D.R.; Ahmed, W.; Banapurmath, N.R.; Hossain, N.; Bashir, S.; Badruddin, I.A.; et al. Effect of Sr@ZnO nanoparticles and Ricinus communis biodiesel-diesel fuel blends on modified CRDI diesel engine characteristics. Energy 2021, 215, 119094. [CrossRef]

16. Soudagar, M.E.M.; Khan, H.M.; Khan, T.M.Y.; Razzaq, L.; Asif, T.; Mujtaba, M.A.; Hussain, A.; Farooq, M.; Ahmed, W.; Shahapurkar, K.; et al. Experimental Analysis of Engine Performance and Exhaust Pollutant on a Single-Cylinder Diesel Engine Operated Using Moringa Oleifera Biodiesel. Appl. Sci. 2021, 11, 7071. [CrossRef]

17. Momirlan, M.; Veziroglu, T.N. The properties of hydrogen as fuel tomorrow in sustainable energy system for a cleaner planet. Int. J. Hydrog. Energy 2005, 30, 795-802. [CrossRef]

18. Litzinger, T.; Stoner, M.; Hess, H.; Boehman, A. Effects of oxygenated blending compounds on emissions from a turbocharged direct injection diesel engine. Int. J. Engine Res. 2000, 1, 57-70. [CrossRef]

19. Abdel-Aal, H.; Sadik, M.; Bassyouni, M.; Shalabi, M. A new approach to utilize hydrogen as a safe fuel. Int. J. Hydrog. Energy 2005, 30, 1511-1514. [CrossRef]

20. Gad, M.; El-Fakharany, M.; Elsharkawy, E. Effect of HHO gas enrichment on performance and emissions of a diesel engine fueled by biodiesel blend with kerosene additive. Fuel 2020, 280, 118632. [CrossRef]

21. Fayaz, H.; Mujtaba, M.A.; Soudagar, M.E.M.; Razzaq, L.; Nawaz, S.; Nawaz, M.A.; Farooq, M.; Afzal, A.; Ahmed, W.; Khan, T.M.Y.; et al. Collective effect of ternary nano fuel blends on the diesel engine performance and emissions characteristics. Fuel 2021, 293, 120420. [CrossRef]

22. Aydin, H.; Ilk1lıc, C.J.A.T.E. Effect of ethanol blending with biodiesel on engine performance and exhaust emissions in a CI engine. Appl. Therm. Eng. 2010, 30, 1199-1204. [CrossRef]

23. Rimkus, A.; Matijošius, J.; Bogdevičius, M.; Bereczky, Á.; Török, Á. An investigation of the efficiency of using O2 and H2 (hydrooxile gas-HHO) gas additives in a ci engine operating on diesel fuel and biodiesel. Energy 2018, 152, 640-651. [CrossRef]

24. Yilmaz, A.C.; Uludamar, E.; Aydin, K. Effect of hydroxy (HHO) gas addition on performance and exhaust emissions in compression ignition engines. Int. J. Hydrog. Energy 2010, 35, 11366-11372. [CrossRef]

25. Kenanoğlu, R.; Baltacığlu, M.K.; Demir, M.H.; Özdemir, M.E. Performance \& emission analysis of HHO enriched dual-fuelled diesel engine with artificial neural network prediction approaches. Int. J. Hydrog. Energy 2020, 45, 26357-26369. 
26. Usman, M.; Farooq, M.; Naqvi, M.; Saleem, M.W.; Hussain, J.; Naqvi, S.R.; Jahangir, S.; Jazim Usama, H.M.; Idrees, S.; Anukam, A. Use of gasoline, LPG and LPG-HHO blend in SI engine: A comparative performance for emission control and sustainable environment. Processes 2020, 8, 74. [CrossRef]

27. Dongare, A.; Kharde, R.; Kachare, A.D. Introduction to artificial neural network. Int. J. Eng. Innov. Technol. 2012, 2, $189-194$.

28. Gul, M.; Shah, A.N.; Aziz, U.; Husnain, N.; Mujtaba, M.; Kousar, T.; Ahmad, R.; Hanif, M.F. Grey-Taguchi and ANN based optimization of a better performing low-emission diesel engine fueled with biodiesel. Energy Sources Part A Recovery Util. Environ. Eff. 2019, 1-14. [CrossRef]

29. Yildizhan, S..; Uludamar, E.; Çalık, A.; Dede, G.; Özcanlı, M. Fuel properties, performance and emission characterization of waste cooking oil (WCO) in a variable compression ratio (VCR) diesel engine. Eur. Mech. Sci. 2017, 1, 56-62. [CrossRef]

30. Yıldırım, S.; Tosun, E.; Çalık, A.; Uluocak, İ; Avşar, E. Artificial intelligence techniques for the vibration, noise, and emission characteristics of a hydrogen-enriched diesel engine. Energy Sources Part A Recovery Util. Environ. Eff. 2019, 41, 2194-2206. [CrossRef]

31. Mujtaba, M.; Masjuki, H.; Kalam, M.; Ong, H.C.; Gul, M.; Farooq, M.; Soudagar, M.E.M.; Ahmed, W.; Harith, M.; Yusoff, M. Ultrasound-assisted process optimization and tribological characteristics of biodiesel from palm-sesame oil via response surface methodology and extreme learning machine-Cuckoo search. Renew. Energy 2020, 158, 202-214. [CrossRef]

32. Gul, M.; Zulkifli, N.W.M.; Kalam, M.A.; Masjuki, H.H.; Mujtaba, M.A.; Yousuf, S.; Bashir, M.N.; Ahmed, W.; Yusoff, M.N.A.M.; Noor, S.; et al. RSM and Artificial Neural Networking based production optimization of sustainable Cotton bio-lubricant and evaluation of its lubricity \& tribological properties. Energy Rep. 2021, 7, 830-839.

33. Ghobadian, B.; Rahimi, H.; Nikbakht, A.; Najafi, G.; Yusaf, T. Diesel engine performance and exhaust emission analysis using waste cooking biodiesel fuel with an artificial neural network. Renew. Energy 2009, 34, 976-982. [CrossRef]

34. Uslu, S.; Celik, M.B. Performance and exhaust emission prediction of a SI engine fueled with I-amyl alcohol-gasoline blends: An ANN coupled RSM based optimization. Fuel 2020, 265, 116922. [CrossRef]

35. Dinjus, E.; Arnold, U.; Dahmen, N.; Höfer, R.; Wach, W. Green fuels-sustainable solutions for transportation. In Sustainable Solutions for Modern Economies; Royal Society of Chemistry: London, UK, 2009; Volume 4, pp. 125-129.

36. Uludamar, E.; Tosun, E.; Tüccar, G.; Yıldızhan, Ş.; Çalık, A.; Yıldırım, S.; Serin, H.; Özcanlı, M. Evaluation of vibration characteristics of a hydroxyl (HHO) gas generator installed diesel engine fuelled with different diesel-biodiesel blends. Int. J. Hydrog. Energy 2017, 42, 23352-23360. [CrossRef]

37. Masood, M.; Ishrat, M.; Reddy, A. Computational combustion and emission analysis of hydrogen-diesel blends with experimental verification. Int. J. Hydrog. Energy 2007, 32, 2539-2547. [CrossRef]

38. Uludamar, E. Effect of hydroxy and hydrogen gas addition on diesel engine fuelled with microalgae biodiesel. Int. J. Hydrog. Energy 2018, 43, 18028-18036. [CrossRef]

39. Dahake, M.; Patil, S.; Patil, S. Effect of hydroxy gas addition on performance and emissions of diesel engine. Int. Res. J. Eng. Technol. 2016, 3.

40. Sun, Z.-Y.; Liu, F.-S.; Liu, X.-H.; Sun, B.-G.; Sun, D.-W. Research and development of hydrogen fuelled engines in China. Int. J. Hydrog. Energy 2012, 37, 664-681. [CrossRef]

41. Premkartikkumar, S.; Annamalai, K.; Pradeepkumar, A. Using hydrogen as a fuel in automotive engines-an investigation. Int. J. Innov. Technol. Res. 2013, 1, 90-93.

42. Ahmed, E.; Usman, M.; Anwar, S.; Ahmad, H.M.; Nasir, M.W.; Malik, M.A.I. Application of ANN to predict performance and emissions of SI engine using gasoline-methanol blends. Sci. Prog. 2021, 104, 00368504211002345. [CrossRef]

43. Kesgin, U. Genetic algorithm and artificial neural network for engine optimisation of efficiency and NOx emission. Fuel 2004, 83, 885-895. [CrossRef]

44. Çay, Y.; Korkmaz, I.; Çiçek, A.; Kara, F. Prediction of engine performance and exhaust emissions for gasoline and methanol using artificial neural network. Energy 2013, 50, 177-186. [CrossRef]

45. Cay, Y. Prediction of a gasoline engine performance with artificial neural network. Fuel 2013, 111, 324-331. [CrossRef]

46. Yusaf, T.; Yousif, B.; Elawad, M. Crude palm oil fuel for diesel-engines: Experimental and ANN simulation approaches. Energy 2011, 36, 4871-4878. [CrossRef]

47. Sayin, C.; Ertunc, H.M.; Hosoz, M.; Kilicaslan, I.; Canakci, M. Performance and exhaust emissions of a gasoline engine using artificial neural network. Appl. Therm. Eng. 2007, 27, 46-54. [CrossRef]

48. Abdalla, A.N.; Tao, H.; Bagaber, S.A.; Ali, O.M.; Kamil, M.; Ma, X.; Awad, O.I. Prediction of emissions and performance of a gasoline engine running with fusel oil-gasoline blends using response surface methodology. Fuel 2019, 253, 1-14. [CrossRef]

49. Dey, S.; Reang, N.M.; Das, P.K.; Deb, M. Comparative study using RSM and ANN modelling for performance-emission prediction of CI engine fuelled with bio-diesohol blends: A fuzzy optimization approach. Fuel 2021, 292, 120356. [CrossRef] 